\title{
Medicinal and Therapeutic Potential of Seed Spices
}

\author{
G Lal* and SS Meena \\ ICAR-National Research Centre on Seed Spices, India
}

Received: June 06, 2018; Published: June 18, 2018

*Corresponding author: G Lal, ICAR-National Research on Seed Spices, Tabiji, Ajmer-305206, Rajasthan, India

\begin{abstract}
India is well known as "Land of Spices" across the world since long back. We have been cultivating these precious spices for fulfilling our various needs since ages. Our ancestors have been using these seed spices for adding taste and flavor in edibles and beverages. It has been used in treatment of various ailments, which is evident from our old literature. These spices are collections of a wide variety of volatile and non-volatile staple dietary additives. These spices have been known for ages as effective therapeutic food. The power of seed spices to impart biological activity is now slowly re-emerging as an area of interest for human health. Nowadays people are moving towards naturopathy because they don't want to bear silently the aftermath of allopathic medicines. Now, time has changed and it's high time for Ayurveda and Unani medicine system to regain its lost glory. In these systems, only natural products are used for preparing medicines, which don't have any side effects.

In this way, the seed spices, which have many medicinal properties, can be a good alternative. Seed spices produce numerous secondary metabolites or phytochemicals, these are naturally occurring, biologically active chemical compounds in plants, where they act as a natural defense system for host plants and that have historically been used as fragrance and flavor agent and pharmaceuticals compounds. These are a gold mine of possibilities in our search for beneficial bioactive compounds for pharmacology and other health related issues. Seed spices influence various systems in the body such as gastrointestinal, cardiovascular and reproductive and nervous systems resulting in diverse metabolic and physiologic actions. Seed spices have a diverse array of natural phytochemicals that have complementary and overlapping actions, including antioxidant effects, Anticancer, Antidiabetic, Antimicrobial Activity, Hypolipidemic effect, Insecticidal, useful in menstrual disorders, helping in digestion, Modulation of hypertension, detoxification enzymes, reduction of inflammation, modulation of steroid metabolism, stimulation of immune system and helps in improve other several human disorder.The present review on therapeutic potential of seed spices namely Ajwain, Coriander, Cumin, Dill, Fennel, Fenugreek and Nigella.
\end{abstract}

Keywords: Seed spices; Ajwain; Coriander; Cumin; Dill; Fennel; Fenugreek; Nigella; Medicinal; Therapeutic; Nutraceutical; Antioxidant

Abbreviations: TAE: Total Alcoholic Extract; HCH: Hexachlorocyclohexan; GST: Glutathione-S-Transferase; LPO: Lipid Peroxidation; COX: Cycloooxygenase Enzyme; TQ: Thymoquinone; MND: Minimal Neurological Deficit

\section{Introduction}

To treat and prevent the diseases use of seed spices have a long history. It is confirmed by many studies that seed spices can be useful medicines, but how to provide scientific evidence and plausible mechanisms for their therapeutic responses is still a major challenge. Therapeutic potential of seed spices to treat multiple symptoms of the metabolic syndrome such as diabetes, obesity, insulin resistance, hypertension and altered lipid profile given focus in this review. Oxidative stress and inflammation have been proposed as initiators of the metabolic syndrome, which prevalent and has become an important financial burden to the healthcare mechanisms in both developing and developed countries. Natural constituents with anti-inflammatory and anti-oxidant properties are present in seed spices. Proper doses of these compounds may be effective in curing the metabolic syndrome. Spices have been known for ages as effective therapeutic food. The power of spices to impart biological activity is now slowly reemerging as an area of interest for human health. Dietary choice remains the basis for maintaining a healthy lifestyle and well-being, despite remarkable advances in medicine and pharmaceutical drug development $[1,2]$.

Besides food being a lifestyle choice, age-old anecdotal reports from many cultures strongly suggest a role for diet as well as Indian spices in both preventive and therapeutic medicine [3,4]. However, the major challenge in the use of seed spices as preventive and therapeutic medicines is in demonstrating their health benefits by scientific means, comparable with the standards applied for pharmaceutical agents [3]. Further, unlike pharmaceutical agents which are administered in predetermined doses as pure and concentrated preparations, seed spices are consumed in combinations and in unmeasured and variable quantities in different cultural settings. Therefore, the major challenge is to provide scientific evidence to define these benefits as well as plausible mechanisms by which these products are effective in a 
disease setting. Around $60 \%$ of the world's population depends on herbal medicine, a broad term including spices, for primary healthcare [5]. Spices are pungent or aromatic substances from dried seeds, fruits, roots, bark and leaves used as additives to colour, flavour, and preserve food. Seed spices are part of everyday cooking and significant quantities may be consumed in India in meales. These data show a realistic possibility to achieve therapeutic doses of the active ingredients in seed spices by dietary consumption alone. However, for many patients, treatment with functional foods or nutraceuticals with enhanced concentrations of the active ingredients of the spices may be necessary.

There is a widespread research effort in India to define the potential health benefits of herbal medicines, including spices, and identify the active ingredients, especially compounds with antioxidant and anti-inflammatory properties $[4,5]$. The seed spices constitute an important group of agricultural commodities and play a significant role in our national economy. Historically, India has been recognized as a land of spices. The states, Rajasthan and Gujarat have together contributed more than 80 per cent of the total seed spices produced in the country. Seed spices produce numerous secondary metabolites or phytochemicals, these are naturally occurring, biologically active chemical compounds in plants, where they act as a natural defense system for host plants and that have historically been used as pharmaceuticals, fragrances, flavor compounds, dyes, and agrochemicals. With the help of modern biological and computational science technology chemoinformatics will help us to development of novel drugs. Even today, these metabolites are a major source of new drugs [6]. They are a gold mine of possibilities in our search for beneficial bioactive compounds for pharmacology and other health related issues. Chemoinformatics opens a new ways to explore seed spices as gold mines for pharmaceuticals industries [7].

They are classified by functional groups, e.g. alcohols, aldehydes, amines, esters, ethers, ketones, terpenes, thiols and other miscellaneous compounds. In spices, the volatile oils constitute these components [8]. Population demographics, increased focus on health versus disease, drive towards self care and self diagnosis and growing knowledge of consumers about traditional medicines are the main driving force for the growth of global phytochemical industry. Today, these metabolites are a major source of new drugs. Plant-derived substances have recently become of great interest owing to their versatile applications. The present review is an effort to present a consolidated report on the current status of research related medicinal and therapeutic potential of Seed Spices namely Ajwain (Trachyspermum ammi L.), Cumin (Cuminum cyminum L.), Coriander (Coriandrum sativum L.), Dill (Anethum sowaL.), Fennel (Foeniculum vulgare Mill.), Fenugreek (Trigonellafoenum-graecum L.) and Nigella (Nigella sativa L.).

\section{Health benefits of Seed Spices: what is the Evidence?}

The contribution of oxidative stress and inflammation in initiating the symptoms of metabolic syndrome is now well-known. Suitable therapeutic interventions targeting these oxidative and inflame-matory processes may be effective in preventing and treating the metabolic syndrome. Several reviews have discussed the use of herbal medicines, including seed spices, in the treatment of the symptoms of metabolic syndrome such as diabetes [4,9], insulin resistance [10], hypertension and other cardiovascular diseases [11] and inflammation [12]. This section deals with the possible therapeutic benefits of the seed spices in the treatment of the symptoms of metabolic syndrome, in particular because of their anti-oxidant or anti-inflammatory effects.

\section{Ajwain (Trachyspermum ammi)}

Name for ajwain (Trachyspermum ammi) is derived from Sanskrit ajamoda or ajamodika. It is a member of the Apiaceae family and considered to be originated in the Egypt and the Indian subcontinent, but also in Iran and Afghanistan. It is having good place in Indian cooking, where it is also known as bishop's weed or carom [13]. There are 26 identified componenets present in ajwain essential oil accounting $96.3 \%$ of the total quantity. Major component found was thymol (39.1\%) followed by p-cymene (30.8\%), $\gamma$-terpinene $(23.2 \%), \gamma$-pinene $(1.7 \%)$; terpinene-4-ol $(0.8 \%)$, while acetone extract of ajwain exhibited the presence of 18 identified components which account for $68.8 \%$ of the total quantity. The main component found are thymol (39.1\%) followed by oleic acid (10.4\%), linoleic acid (9.6\%), $\gamma$-terpinene $(2.6 \%)$, p-cymene (1.6\%), palmitic acid (1.6\%) and xylene (0.1\%) [14].

Ajwain also used sometimes as an ingredient in barbered, a spice mixture favored in Eritrea and Ethiopia [15, 16]. Ajwain is an annual herbaceous plant having 30-70 cm (1-2 ft) height, with feathery leaves and red flowers. Ripe seeds are dried and threshed $[17,18]$ manually and/ or mechanically. Ajwain seed (fruit) is reported to have antifungal/antibacterial, antiseptic and antithelminitic effects [19]. The major phenolic compound thymol found in ajwain has been reported to be an antispasmodic, germicide and antifungal agent [20]. The principle active constituents of ajwain oil are phenols, mainly thymol (35-60\%) and some carvacrol [21]. Both the phenols thymol and carvacrol are having antiseptic, expectorant and antitussive properties [22]. Thymol also has antiseptic activity and carvacrol possesses antifungal properties [23].

\section{Medicinal and Pharmacological Properties}

a) Gastro protective activity: Ajwain (Trachyspermum ammi) seed menifest anti-ulcer activity. Animals pre-treated with ethanolic extract exhibit remarkable decrease in ulcer protection per cent and ulcer index in all models. The findings inferred that the extract showed significant protection by reducing ulcerative lesions when compared with control group of animals [24].

b) Abdominal pain: Ajwain is considred as traditional medicine for relieving abdominal pain especially in rural hemlets from time immemorial. A traditional remedy of ajwain for abdominal pain is to make a standard infusion using 2 tsp of bruised seeds or 1 tsp of ajwain powder to $570 \mathrm{ml}$ cold water in a small pan. Boil, simmer for up to 2 minutes and then strain for use. It can be used for treating respiratory and digestive infections, asthma, cramp muscle spasms, colic griping pains, 
edema, arthritis and rheumatism. Wound cleaning and skin infection treatment can also be done by external use of ajwain as an antiseptic. Like all medicinal herbs, ajwain is grown organically to avoid its intrinsic properties being partly or completely eliminated by the presence of foreign substances [25].

c) Hepatoprotective activity: The results revealed [26] that hepatoprotective actions in vivo of ajwain was $80 \%$ protective in mice against a normally-lethal dose of paracetamol $\left(1 \mathrm{~g} \mathrm{~kg}^{-1}\right)$, it prevented the $\mathrm{CCl}_{4}^{-}$induced prolongation of pentobarbital sleeping time in mice and it tended to normalize the high serum levels of liver enzymes caused by $\mathrm{CCl}_{4}^{-}$induced liver damage in rats.

d) Anti-spasmodic: Ajwain seeds and its oil used for medicine. The seed can also be powdered with the help of grinder or pin mill and tied tightly in a thin cloth to treat migraine headaches and heavy colds by inhaling the aroma frequently throughout the day. Take $100 \mathrm{~g}$ of ajwain, $50 \mathrm{~g}$ of ginger power and $25 \mathrm{~g}$ of black salt and crush them together to be put in a dry container. Applying hot formation on the area of pain will bring faster relief $[24,27]$.

e) Digestive stimulant actions: Ajwain would increase the secretion of gastric acid nearly four times. In experimental rats in vivo, the addition of ajwain to the diet reduced food transit time and also enhanced the activity of digestive enzymes and/ or caused a higher secretion of bile acids [24].

f) Antiflatulent: Traditionally ajwain is used to allay the retention of gas and flatulence. It is in practice in rural areas to use ajwain in a very special way. One famous preparation can be made by taking $500 \mathrm{~g}$ ajwain seed, $20 \mathrm{~g}$ rock salt, $20 \mathrm{~g}$ black salt and $20 \mathrm{~g}$ table salt. Put all of these in $500 \mathrm{ml}$ lemon juice for a few days to be dried at its own. Taking with warm water half to one teaspoonful of this specially prepared ajwain mixture is an excellent home remedy to treat abdominal gas anorexia, nausea, travel sickness and vomiting [28].

g) Antimicrobial influence: Ajwain is also known for its excellent antimicrobial influence. It protect the food stuffs against microbial spoilage, conducting laboratory assays of antimicrobial efficacy in vitro and its use as antimicrobials in humans are also investigated. The active compounds of ajwain viz., carvacol and thymol considered to be responsible for the antimicrobial activity. Third generation antibiotics and multidrug resistant microbial pathogens can be killed by thymol and thus works as a plant based $4^{\text {th }}$ generation herbal antibiotic formulation [29,30].

h) Antifungal effect: Antifungal effect of volatile oil of ajwain seeds on 10 fungi (Alternaria grisea, A. tenuissima, Acrophialophora fusispora, Curvularia lunata, Drechslera tetramera,Fusarium chlamydosporum, F. poae, Myrothecium roridum, Papulaspora sp. and Rhizoctonia solani) was tested and found to curb the growth of all tested fungi by $72-90 \%$. Phenolic compounds, such as carvacol and thymol, are known to be either bactericidal or bacteriostatic agents depending on the used concentration [14,31].

i) Anti-inflammatory power: Anti-inflammatory power of the Total Alcoholic Extract (TAE) and Total Aqueous Extract (TAQ) of the Ajwain seeds was also determined. The TAE and TAQ shown significant $(\mathrm{p}<0.001)$ antiinflammatory activity in both the animal models. The weights of the adrenal glands were found to be significantly increased in TAE and TAQ treated animals. The TAE and TAQ extracts from the ajwain seeds exhibit significant anti-inflammatory potential [32].

j) Anthelmintic effect: Ajwain seed having anthelmintic influence and very much effective against specific helminths, e.g. Ascaris lumbricoides in humans and Haemonchus contortus in sheep. The activity exerted by interference with the energy metabolism of parasites through potentiation of ATPase activity and thus loss of energy. Ajwain plant has also been reported to have cholinergic activity with gut's peristaltic movements, thus helps in expulsion of intestinal parasites [33].

k) Nematicidal action: Wilt disease in pine caused by the pinewood nematode (PWN), Bursaphelenchus xylophilus. Nematicidal activity of ajwain oil constituents (camphene, pinene, myrcene, limonene, terpinene, terpinen-4-ol, thymol and carvacrol) found to be against PWN. Amino and hydroxyl groups have also been reported as target sites of methyl isothiocyanate in nematodes. Essential oils have been reported to interfere with the neuromodulator octopamine or GABA gated chloride channels of insect pests. Carvacrol and thymol are found to be very effective against PWN.These findings confirm that the nematicidal activity of ajwain oil is mainly attributed to the activity of carvacrol and thymol [34,35].

I) Amebiasis: In the Unani system, Ajwain is used as a crude drug to enhance the body's resistance and is prescribed in amebiasis [36].

m) Antihypertensive and broncho-dilating property: The antihypertensive effect of Trachyspermum ammi administered intravenously in vivo and the antispasmodic and broncho-dilating actions. In vitro showed that calcium channel blockade has been found to mediate the spasmolytic effects of plant materials and it is being considered that this mechanism contributed to their observed result and supported the traditional use of Trachyspermum ammi in hyperactive disease states of the gut such as colic and diarrhea as well as in hypertension [26].

n) Antitussive actions: These effects of aerosols of two different concentrations of aqueous and macerated extracts and carvacrol, codeine and saline were tested by counting the number of coughs. Significant reduction of cough number obtained in the presence of both concentrations of aqueous and macerated extracts and codeine $(\mathrm{p}<0.001$ for extracts and $\mathrm{p}<0.01$ for codeine) [37].

o) Antiplatelet-aggregatory property: A research study [38] was intended to support the traditional use of ajwain in 
women post parturition. Antiplatelet-aggregatory experiments in vitro with blood from human volunteers, it that a dried ethereal extract of ajwain seeds, inhibited aggregation of platelets induced by collagen, arachidonic acid, and epinephrine.

p) Hypolipidemic action: In albino rats antihyperlipidemic effect of ajwain seed has been obtained. It was assessed that powder made by ajwain seed at a dose rate of $2 \mathrm{~g} \mathrm{~kg}^{-1}$ body weight and its equivalent methanol extract were extensively effective in lipid lowering action by decreased LDL-cholesterol, total cholesterol, triglycerides and total lipids [39].

q) Antilithiasis and diuretic property: It was found in a study conducted on antilithiasis and diuretic property in vivo that ajwain was not effective in increasing the 24 hour urine production. Hence, it was concluded that the traditional use of T. ammi in the treatment of kidney stones was not supported by their experimental evidence [40].

r) Abortifacient and galactogogic effect: At ICAR-National Dairy Research Institute, Karnal, India a study was carried out on the estrogenic content in some herbs which are traditionally used to increase milk yield in dairy cattle. Ajwain has also been traditionally used as a galactogogue in human beings. Total phytoestrogen content of dry Trachyspermum ammi seed was $473 \mathrm{ppm}$, which was the second highest in the list of eight herbs tested [41].

s) Detoxification of aflatoxin action: Ajwain seed extract exhibited maximum degradation of aflatoxin G1 (AFG1). Aflatoxin detoxifying action of the seed extract reduced significantly while boiling. Remarkable levels of degradation of other aflatoxins namely, AFB1, AFB2 and AFG2 by the dialyzed seed extract were also recorded. Time course study of AFG1 detoxification by dialyzed ajwain seed extract exhibited more than $91 \%$ degradation at $24 \mathrm{~h}$ and $78 \%$ degradation within $6 \mathrm{~h}$ after incubation [42]

t) Ameliorative influence: Influence of ajwain seed extract on hexachlorocyclohexan $(\mathrm{HCH})$-induced oxidative stress and toxicity in rats were studied. Ajwain seed extract pre-feeding resulted in increased GSH, GSH-peroxidase, SOD, G-6-PDH, catalase, Glutathione-S-Transferase (GST) activities and decreased hepatic levels of lipid peroxides. It was inferred from the investigation that $\mathrm{HCH}$ administration as in produce the hepatic free radical stress, causing toxicity, which could be reduced by the dietary ajwain seed extract [14].

u) Coriander (Coriandrum sativum L.): Coriander (Coriandrum sativum L.) is an important seed spice crop belongs to Apiaceae family. It is a well-known herb, originated in the native to Europe and Western Asia.Coriander is now widely cultivated in many other parts of the world for its leaves, seeds and essential oil production. It is commonly grown in India, Pakistan, Bangladesh, Russia, Central Europe, Morocco, and China. The volatile oil content of the spice can vary considerably according to the type and source and usually ranges from 0.1 to $1.7 \%$ and, in some cases, up to $2.7 \%$. European coriander is mainly of the small fruited type and usually has volatile oil content greater than $0.4 \%$, with the highest values exhibited by some Russian cultivars. It is generally used in gastrointestinal complaints such as anorexia, dyspepsia, flatulence, diarrhoea, griping pain and vomiting [43]. The stems and leaves contain caffeic, chlorogenic, ferulic and gallic acids [44]. The seeds were effective as an antidiabetic agent administered as $6.25 \%$ in food in streptozotocin-diabetic mice [45], and as a hypolipidaemic agent as $10 \%$ in food in rats fed $15 \%$ coconut oil and $2 \%$ cholesterol [46].

Continuous intravenous infusion of the crude aqueous extract of coriander (40 and $100 \mathrm{mg} / \mathrm{kg}$ ) induced dose-dependent diuresis, natriuresis, kaliuresis, increased chloride excretion and increased glomerular filtration rate in anaesthetized Wistar rats [47]. Alcoholic extract of coriander $(200 \mathrm{mg} / \mathrm{kg})$ decreased fasting serum glucose concentration and increased insulin release from pancreatic $\beta$-cells in streptozotocin-induced diabetic rats [48]. Oral intake of fruit powder ( $8 \% \mathrm{w} / \mathrm{w}$ of food) in cholesterol-fed rats decreased plasma total cholesterol, LDL-cholesterol and total lipid concentrations, while increasing the HDL-cholesterol [49]. The composition of the volatile oil, which determines the odour and flavour character, contains both volatile and fixed oil. The volatile oil is rich in beneficial phytonutrients, including carvone, geraniol, limonene, borneol, camphor, elemol, and linalool. Linalool is the major constituent (25-80 per cent) [50]. Coriander seeds have a health-supporting reputation that is high on the list of the healing spices. In parts of Europe, coriander has traditionally been referred to as an anti-diabetic plant. In some parts of India, it has traditionally been used for its anti-inflammatory properties.

\section{Medicinal and Pharmacological Properties}

a) Antibacterial activity: Essential oils from commercial samples of coriander were showed antibacterial, antifungal and antioxidant activities. The essential oils of coriander showed a high degree of inhibition against twenty-five genera of bacteria and one fungal species (Aspergillus niger) [51].

b) Hypoglycemic activity: Coriander has been documented as a traditional treatment for diabetes from immortal time. Coriander lowered the blood sugar when added to the diet of diabetic mice. The antihyperglycemic action of coriander is associated with stimulation of insulin secretion and enhancement of glucose uptake and metabolism by muscle, reflecting the effects of more than one active constituent. Coriander therefore, represents a possible antihyperglycemic dietary adjunct and potential source of orally active agent(s) for diabetes therapy. The presences of antihyperglycaemic, insulin releasing and insulin- like activity in coriander were demonstrated by Selvan [52].

c) Hypolipidemic activity: The study shows that the concentrations of cholesterol and cholesterol to phospholipid ratio decreased while the level of phospholipid increased. Coriander plays a protective role against the deleterious effects in lipid metabolism in experimental colon cancer $[53,54]$. Some 
of the acids present in coriander viz. linoleic acid, oleic acid, palmitic acid, stearic acid and ascorbic acid (vitamin-C) are very effective in reducing the cholesterol level in the blood. They also reduce the cholesterol deposition along the inner walls of the arteries and veins [55].

d) Aflatoxin control: The essential oil of coriander showed significant inhibitory effects of on the mycelial growth and toxin produced by A. ochraceus [56]. The potential of coriander oil in the control of A. niger, Saccharomyces cerevisiae, Mycoderma sp., L. acidophilus and Bacillus cereus [57].

e) Antioxidant activity: Leaf and seed extracts of coriander and coriander oil were tested for their antioxidant activity using different bioassay techniques and a positive correlation were found between total phenolic content in the extracts and antioxidant activity. Coriander leaves showed stronger antioxidant activity than the seeds [58].

f) Cumin (Cuminum cyminum L.): Cumin (Cuminum cyminum L.) is an annual herb that belongs to the family Apiaceae having the somatic chromosome number of $2 n=14$. The Latin name Cuminum is derived from the Greek "Kuminon", originated probably from the old Babyleniun name for cumin'ka-ma-nu'. Cumin, native of Egypt, is now grown in most hot regions like India, North Africa, China and America. The spice is especially associated with Morocco, where it is often smelt in the abundant street cookery of the medinas. Cumin was known to the Egyptians five million years ago. Its seeds have been found in the old kingdom pyramids. The Romans and Greeks used it medicinally and cosmetically to induce a pallid complexion. Cumin and value added products from cumin are used in food flavoring and perfumery. Cumin contains volatile oil (3-4\%), the major active principle of volatile oil is cuminaldehyde, which is present to an extent of $45-50 \%$ and is an important phytochemical and possesses many health benefits [58], reported that the main constituents of cumin seed oil were cuminaldehyde which is responsible for its characteristic odour other components are -pinene, -terpinene, p-mentha-1,3-dien7-al, p-mentha-1,4-dien-7-al, and p-cymene [59].

Cumin seed contains moisture (7\%), volatile oil (3-4\%), protein $(12 \%)$, total ash $(10 \%)$, fiber $(11 \%)$, carbohydrate $(33 \%)$, starch $(11 \%)$, and fat (15\%). The composition of cumin changes according to the region and climate where it is grown. Cumin seeds are a common dietary spice consumed in fairly large quantities in India. They are widely used in Ayurvedic medicine for treatment of dyspepsia, diarrhoea and jaundice [60]. Cuminaldehyde is suggested as the active ingredient in cumin seeds (Figure 1) [3,7]. An aqueous extract of cumin seeds prevented the accumulation of advanced glycation end-products due to fructose-mediated in vitro glycation of eye lens soluble proteins [61]. Hypoglycaemic effects of cumin seeds were also observed in normal rabbits [62]. Dietary cumin showed marked hypoglycaemic responses in streptozotocindiabetic rats by reducing blood and urinary glucose concentrations [63]. An aqueous extract of seeds lowered blood glucose and plasma and tissue lipid concentrations in alloxan-induced diabetic rats [60]. Cumin also has a number of medicinal uses and helps in curing many diseases. In Ayurvedic medicine, cumin is considered a warming spice, invaluable for digestion. It is also a cleansing spice that helps burn toxins and enhances the appetite. Traditional uses of cumin include anti-inflammatory, diuretic, carminative, and antispasmoidic. It has also been used to treat dyspepsia, jaundice, diarrhea, flatulence, and indigestion. Cumin powder is used as a poultice and smoked in a pipe and also taken orally.

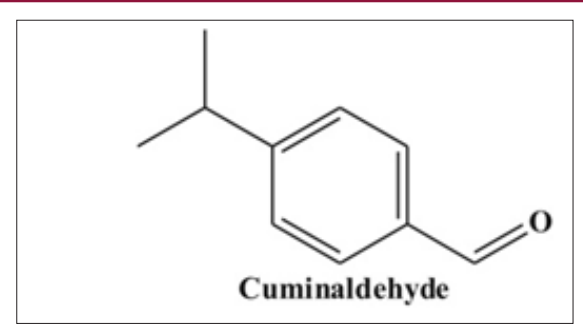

Figure 1: Cuminaldehyde, an active ingredient of cumin

\section{Medicinal and Pharmacological Properties}

a) Antioxidant Activity: Cumin seeds contain flavonoids,viz., apigenin and luteolin, which are now generally recognized to have antioxidant activity. The petroleum ether soluble fraction of cumin has been reported to have antioxidant activity [64]. Cuminaldehyde has been demonstrated to scavenge the superoxide anion [65].

b) Blood Platelet Aggregation: Cumin extract in etherinhibited arachidonate-induced platelet aggregation in human platelets in a dose-dependent manner [66].

c) Antidiabetic: Dietary cumin countered other metabolical terations as revealed by lowered blood urea level and reduced excretions of urea and creatinine by diabetic animals [67]. The elevated plasma urea level of diabetic animals was significantly lowered by about $50 \%$ by dietary cumin. Cumin has been used as one of the ingredients of a herbal antidiabetic drug, which was found to be effective in human subjects [68].

d) Antimicrobial Activity: Essential oil and alcoholic extract of cumin has shown antimicrobial activity against Klebsiella pneumoniae ATCC 13883 and ceftazidime-resistant strain. Cumin oil and cuminaldehyde have been reported to exhibit strong larvicidal and antibacterial activity. The essential oil and alcoholic extract of cumin seed could be used in medicinal industries (disinfectant or antiseptic) [69].

e) Anticancer Effects: The spice appears to have an anticancer effect as demonstrated by the ability of cumin seeds to inhibit the induction of gastric squamous cell carcinomas [70]. In rats fed with cumin, a protective effect against induced colonic cancer was demonstrated.

f) Dillseed (Anethum sowa L.): Dill seed (Anethum sowa L.) also known as Bengali- Shulfa, belonging to the family Apiaceae, comes undergenus Anethumandit is an annualand winter spice crop in Bangladesh. It is mostly grown in the northern part of Bangladesh. A variant called Indian dillorsowa (Anethum sowa 
Roxb.) is largely cultivated in India, Bangladesh, Egypt and Japan. Dill seed is very much benecial for human health and having ability to boost digestion, and gives relief from insomnia, respiratory disorders, hiccups, dysentery, diarrhea, menstrual disorders and different types of cancers. It is considered to be a powerful boost for immune system of human beings and also good for oral care. Dill seed is laso having properties to protect from bone degradation and arthritis. Furthermore, it can reduce excess gas and is considered a carminative. Various different compounds have been isolated from the seeds, leaves and inflorescence of this plant; 17 volatile compounds have been identified.

The main constituents of dill oil which is pale yellow in color, darkens on keeping, with the odor of the fruit and a hot, acrid taste are a mixture of a paraffin hydrocarbon and 40 to $60 \%$ of d-carvone (23.1\%) with d-limonene (45\%). It also consists of $\alpha$-phellandrene, eugenol, anethole, flavonoids, coumarins, triterpenes, phenolic acids and umbelliferones. The fruit yields about 3.5\% of the oil; its specific gravity varies between 0.895 and 0.915 . Carvone and limonene are monoterpenes, which are present as main constituent of dill oil from fruits [71] $\alpha$-phellandrene, dill ether and myristicin are the compounds, which form the important odor of dill herb
[72,73]. Monoterpenes are 10-carbon members of the isoprenoid family of natural products; they are widespread in the plant kingdom and are often responsible for the characteristic odors of plants. These substances are believed to function principally in ecological roles, serving as herbivore-feeding deterrents, antifungal defenses and attractants for pollinators [74].

Seventeen compounds have been identified in Indian dill leaf [75]. The several applications of carvone are as fragrance and flavor, potato sprouting inhibitor [76], antimicrobial agent and building block and biochemical environment. D-limonene is one of the most common terpenes in nature. It is a major constituent in several citrus oils (orange, lemon) being an excellent solvent of cholesterol; d-limonene has been used clinically to dissolve cholesterol-containing gallstones. It has chemo preventive and chemotherapeutic activities and also reported to have low toxicity in pre-clinical studies [77]. Myristicin is a naturally occurring insecticide and an important compound of essential oil [78,79]. Anethole is a terpenoid that is present in minor quantity in Anethum, but is also found in essential oil of anise and fennel [80] It is used as a flavoring substance. P-anisaldehyde has a strong aroma and is an important component in pharmaceuticals and perfumery (Table 1).

Table 1: Brief health potential uses of major seed spices.

\begin{tabular}{|c|c|c|}
\hline Seed Spices & Major phytochemicals & Medicinal uses \\
\hline Ajwain & $\begin{array}{l}\text { Thymol, oleic acid, linoleic acid, } \gamma \text {-terpinene, } \\
\text { p-cymene, palmitic acid and xylene }\end{array}$ & $\begin{array}{l}\text { Digestive, pungent, mild stimulant, stomachic, carminative, aphrodisiac, } \\
\text { antiflatulence, antiseptic, antifungal, antibacterial, antithelminitic, } \\
\text { antispasmodic, germicide, antitussive and expectorant }\end{array}$ \\
\hline Cumin & cuminaldehyd, $\beta$-pinene, $\gamma$-terpinene & $\begin{array}{l}\text { Gastrointestinal, reproductive, nervous and immune system. Antimicrobial, } \\
\text { antioxidant and chemoprotective activity. }\end{array}$ \\
\hline Coriander & $\begin{array}{l}\text { Linalool, carvone, geraniol, limonene, borneol, } \\
\text { camphor, elemol }\end{array}$ & $\begin{array}{l}\text { Digestive, carminative, diuretic, tonic, stimulant, refrigerant, aphrodisiac, } \\
\text { analgesic, anti- inflammatory, antioxidant, insulin-like and anti-spergillus } \\
\text { activity. }\end{array}$ \\
\hline Dill & Limonene, carvone, anethofuran & $\begin{array}{c}\text { Digestion, insomnia, diarrhea, dysentery, menstrual disorders, respiratory } \\
\text { disordrers, arthritis, gas, carminative, pain killer, antipyretic, stomachic } \\
\text { andantiflatulence }\end{array}$ \\
\hline Fennel & Anethole, fenchone, phenols & $\begin{array}{l}\text { Aromatherapy, antioxidant, hepatoprotective, anticancer, Stimulant, } \\
\text { carminative, stomachic, emmenagogue, refrigerant, cardiac stimulant, } \\
\text { antiemetic, aphrodisiac, anthelmintic and antimicrobi }\end{array}$ \\
\hline Fenugreek & $\begin{array}{l}\text { Steroidal saponins(diosgenin), Galactomanan, } \\
\text { 4-HIL }\end{array}$ & $\begin{array}{l}\text { Carminative, tonic, aphrodisiac, emollient, antibacterial, used in vomiting, } \\
\text { fever, anorexia, colonitis, complementary medicines for cancer therapy, } \\
\text { diabetes and oral contraceptive. }\end{array}$ \\
\hline Nigella & $\begin{array}{l}\text { Nigellone, nigellicine, nigellimine, nigellimine- } \\
\text { N-oxide,4-ethyl-lophenol, } \beta \text {-amyrin, } \\
\text { butyrospermol, cycloartenol, } 2 \text {-4-methylo- } \\
\text { cycloartanol, taraxerol, tirucallol, }\end{array}$ & $\begin{array}{l}\text { Diuretic, antihypertensive, antidiabetic, anticancer, immunomodulatory, } \\
\text { analgesic, antimicrobial, anthelmintics, analgesics and anti-inflammatory, } \\
\text { spasmolytic, bronchodilator, liver tonic, gastroprotective, epatoprotective, } \\
\text { renal protective and antioxidant properties }\end{array}$ \\
\hline
\end{tabular}

\section{Medicinal and Pharmacological Properties}

a) Medicinal uses: Anethum is used as an ingredient in gripe water, given to relieve colic pain in babies and flatulence in young children [81]. The seed is aromatic, carminative, mildly diuretic, galactogogue, stimulant and stomachic [82] The essential oil in the seed relieves intestinal spasms and griping, helping to settle colic $[78,83]$ The carminative volatile oil improves appetite, relieves gas and aids digestion. Anethum stimulates milk flow in lactating mothers and is often given to cattles for this reason. It also cures urinary complaints, piles and mental disorders [84].

b) Prevents Insomnia: The essential oil of dill is having properties like stimulating, sedative and hypnotic, those are they stimulate [85] as well as pacify. The essential oils in dill are no exception. Vitamin-B complex and flavonoids present in essential oil of dill seed activate the secretion of some enzymes and hormones which are having calm and hypnotic effects, hence helping people get a good night's sleep. 
c) Maintains Bone Health: Dill seed is also having good quality of calcium [86] of which, is an important element [86] protect from bone loss and bone mineral density reduction. Millions of people affected by osteoporosis each year and calcium, along with other essential minerals, is a key component in the proper growth and development of bones and the repair of injured bones as well.

d) Manages Diabetes: Dill seed is also having antidiabetic properties [81] diabetes and helps in management of insulin levels. It also reduces the fluctuations of serum lipids and insulin levels in corticosteroid-induced diabetes.

e) Prevents Excess Gas: As a well-known [87] carminative, dill can help prevent the embarrassing condition of excessive gas. It is not only an uncomfortable condition to experience in public, but if gas continues to build up, it can actually be a dangerous situation where it presses on the delicate organs of the chest cavity. A carminative force gas downward through the digestive tract and allows it to leave the body in a safe way.

f) Boosts Immunity: Dill has long been associated with antimicrobial activity [88]. It can prevent a number of microbial infections of the body including the infections result in open wounds or small cuts on the skin.

g) Calms Hiccups: Dill seed is having the properties to calm hiccups which is caused due totrapped gas, its repeated upward movement through the food pipe, certain allergies, hypersensitivity, hyperactivity, and nervous malfunctioning. It also acts as a carminative, helps the expulsion of gases and also reduces gas formation; while as a sedative, dill seed helps to calm down hiccups [89].

h) Cures Diarrhea: Indigestion and microbial actions are the causes of diarrhea. Dill seed is having very good digestive properties can be quite helpful in indigestion. It is also helpful to cure diarrhea by inhibiting [90] microbial infections due to the monoterpenes and flavonoids present in its essential oils, which are germicidal or bactericidal in nature.

i) Treats Dysentery: Dysentery is primarily caused [89] due to fungal infections. Dill essential oil is disinfectant in nature and it helps to inhibit fungal infections effectively.

j) Prevents Cancer: Let's turn our attention to the monoterpenes we have been talking about. Monoterpenes are chemopreventive, and since they are stimulating in nature, they activate the secretion of an enzyme called glutathione-Stransferase (the radical glutathione is an effective antioxidant) which is very effective in neutralizing carcinogens. It is particularly effective at neutralizing cyano- and benzoderivatives and free radicals, thereby protecting the body from cancer. The other antioxidants in the essential oils of dill also contribute to cancer prevention [83].

k) Fennel (Foeniculum vulgare Mill.): Fennel (Foeniculum vulgare Mill.) belongs to family Apiaceae is a native of Southern Europe and Mediterranean region. It is widely cultivated throughout the temperate and subtropical regions of the world and major growing countries are Romania, Russia, Germany, France, Italy, India, Argentina and USA. It is also a very popular medicinal and economic plant in Asian countries. The herb has many culinary and traditional medicine uses. The bulb, young shoots, leaves and fully ripened and dried fruits are commonly used for homemade remedies. Its aromatic fruits have been used as a culinary spice in many countries [91]. Fennel herbal tea is a common household remedy traditionally used for the treatment of a variety of symptoms of the gastrointestinal and respiratory tract [92]. The chemical constituents from the fennel include essential oil, fatty acid, phenylpropanoids, monoterpenids, sesquiterpenes and coumarins.

It also contains triterpenoids, tannins, flavonoids, cardiac glycosides, saponins, and other types of compounds. The relative content of essential oil in fennel fruits was about 3.0 to $5.0 \%$ by weight. The essential oil of the most important fennel variety (var. dulce) contains anethol (50-80\%), limonene (5\%), fenchone (5\%), estragol (methyl-chavicol), safrol, alpha-pinene (0.5\%), alphaphellandrine, camphene, beta-pinene, beta-myrcene and p-cymen. In contrast, the uncultivated form (var. vulgare) contains often more essential oil, but since it is characterized by the bitter fenchone (12 to $22 \%$ ), it is of little value [93]. The essential oil of fennel fruits is used for flavouring purpose, cosmetic and pharmaceutical products $[94,95]$, identified 78 compounds from fennel fruits by GC-FID-MS, representing more than $98 \%$ of the oils. The seeds of fennel contain about $20 \%$ fatty acids and petroselinic acid is a characteristic fatty acid of fennel oil. The level of petroselinic acid could be as high as 70 to $80 \%$ [96]. The chemical analysis of the acetone extract of fennel showed that linoleic acid (54.9\%), palmitic acid (5.4\%) and oleic acid (5.4\%) were major components in acetone extract [97]. There has been a growing interest in phenolic components of fruits and vegetables, which may promote human health or lowering the risk of disease. Aqueous extract of fennel fruits contains rich phenolic compounds. Many of them have antioxidant activities, such as 3-caffeoylquinic acid, 4-caffeoylquinic acid, rosmarinic acid, eriodictyol-7-orutinoside, quercetin-3-o-galactoside, kaempferol3-orutinoside and kaempferol-3-o-glucoside. Besides, these compounds, fennel was reported containing hydroxylcinnamic acid derivatives, flavonoid glycosides and flavonoid aglycones [98].

Flavonoids were generally considered as an important category of antioxidants in the human diet. Some flavonoids such as quercetin arabinoside were identified from Foeniculum vulgare [99]. Flavonoids such asquercetin, rutin and isoquercitrin were reported to have the immunomodulatory activities. It is prescribed as an aromatic stomachic and treats various conditions, particularly rheumatism, cold pain and stomach. Fennel essential oil possessed carminative and stimulant activities as well as spasmolytic actions on the smooth muscles of experimental animals [100]. Furthermore, it possessed analgesic, anti-inflammatory and antioxidant activities. Oral administration of methanol extract of fennel exhibited inhibitory effect against acute and subacute inflammatory diseases and showed a central analgesic effect by inhibition of the allergic reactions. It significantly decreased the high density lipoprotein- 
cholesterol level, thus decreasing the peroxidative damage [101]. The essential oil of fennel exhibited antibacterial and antiviral activities [102]. The aqueous and ethanol extracts of fennel exhibited potential antioxidant properties in vitro studies [103]. It might be useful for the treatment of cognitive disorders such as dementia and Alzheimer's disease [104].

\section{Medicinal and Pharmacological Properties}

a) Antimicrobial, antibacterial and antifungal activities: Antimicrobial activities of plant oils and extracts have many applications, including raw and processed food preservation, pharmaceuticals, alternative medicine and natural therapies. Chloroform soluble fraction from fennel plant parts showed a robust antimicrobial action against fungi and bacteria. The compounds found in fennel like dillapiol, dillapional, psolaren, scopoletin, bergapten and imperatorin were found to be having antimicrobial actions against Aspergillus niger, Bacillus subtilis and Cladosporium cladosporioides [105]. Essential oils from the fruits of fennel showed significant antibacterial activity to Escherichia coli and Bacillus megaterium [106]. Fennel essential oils may be useful natural bactericides for the control of bacterial diseases of plants. Essential oils components viz., anethole, fenchone and camphor exhibited antifungal propetrties against C. cladosporioides, Penicillium helianthi and Trichophyton mentagrophytes, however Penicillium ochrochloron, Penicillium funiculosum and Trichoderma viride were found resistant species [97,107]. Dichloromethane extracts and essential oils from $F$. vulgare showed antifungal activity against Candida albicans. It could be the candidate for a new antifungal agent for candidiasis and other fungal diseases [108].

b) Antioxidant activities: Now a day's naturally-occurring antioxidants are popular to use to protect human beings from oxidative stress damage. Fennel was known as excellent sources of nature antioxidants and contributed to the daily antioxidant diet [109]. Wild fennel was found to exhibit a radical scavenging activity with higher content phenolic and flavonoid than medicinal and edible fennel, and the aerial parts of the Italian populations showed the highest DPPH scavenging activity [110]. The volatile oil exhibited strong antioxidant influence as compared to butyrated hydroxyanisole and butylated hydroxytoluene $[6,97]$ concluded that fennel genotype RF-101 show higher TPC, TFC and antioxidant activity in methanolic extract of oleoresin in comparison volatile oil of fennel seeds.

c) Acaricidal activity: Fennel oil show significant acaricidal activity and works very well against Dermatophagoides pteronyssinus and Dermatophagoides farinae. The main bioactive component is fenchone. $p$-anisaldehyde was the most toxic compound to D. Farina. Carvone characterized as bioactive constituent to potential house dust mite Tyrophagus putrescentiae [111].

d) Estrogenic activity: Fennel oil was reported to exhibit estrogenic activity, promote menstruation, alleviate the symptoms of female climacteric, and increase libido [112]. e) Insecticidal activity: The fennel extracts was reported to have insecticidal activity against different mites and insects [107]. An important compound found in fennel namely Transanethole was known to have effective mosquito larvicidal activity [113]. Fennel extracts were found toxic against Culex pipiens larvae, and terpineol and 1,8-cineole were the most effective components against Anopheles dirus and Aedes aegypti. Hence, it was suggested that fennel can be used as an alternative of synthetic insecticides [111].

f) Hepatoprotective activity: Fennel essential oil could inhibit the $\mathrm{CCl}_{4}$ induced acute hepatotoxicity. D-limonene and b-myrcene of the oil might be the potential candidates [112].

g) Fenugreek (Trigonella foenum graecum L): Fenugreek is commercially important seed spice crop due to its multifarious uses. It is belongs to the family Fabaceae.There are two cultivated species of genus Trigonella viz. foenum-graecum (common fenugreek) and corniculata (Kasuri type fenugreek). Centre of origin of fenugreek is South-Europe, Mediterranean area and Western Asia. The major fenugreek producing countries are India, Argentina, Egypt, Southern France, Morocco, Spain, Turkey and China. Fenugreek, a strongly scented annual herb, is recommended for the treatment of rheumatism in traditional medicine. Saponins, glycoside-D and trigofoenoside-A are major components in the seeds [113], while alkaloids, cardiac glycosides and phenols are found in the leaf extract [114]. The steroidal saponins present in the seeds as parent compounds for physiological steroid production could influence the local inflammatory response [115,116].

Galactomannan, a guar gum comprising approx. 50\% of the seed weight is postulated as another active ingredient in fenugreek seeds [117]. In high sucrose-fed rats, galactomannan feeding reduced appetite, body weight gain, glycemic response, plasma insulin concentrations and plasma triglycerides and total cholesterol concentrations [118]. In human studies, galactomannan reduced post-prandial blood glucose concentrations $[119,120]$ and improved insulin sensitivity in both non-diabetic [121] and diabetic subjects [122]. Feeding guar-galactomannan fibre reduced both total and LDL cholesterol concen-trations in healthy and type 2 diabetic subjects [123]. It has a long history as both a culinary and medicinal herb. The seeds of fenugreek are commonly used as a spice in food preparations due to the strong flavour and aroma.

Fenugreek seed contains $45-60 \%$ carbohydrates, mainly mucilaginous fiber (galactomannan); $20-30 \%$ proteins high in lysine and tryptophan; 5- 10\% fixed oils (lipids); pyridine type alkaloids, mainly trigonelline $(0.2-0.36 \%)$ choline $(0.5 \%)$, gentianine and carpaine; flavonoids, such as apigenin, luteolin, orientin, quercetin, vitexin and isovitexin; free amino acids, such as 4-hydroxyisoleucine; arginine, histidine and lysine; calcium and iron; saponins (0.6-1.7\%); cholesterol and sitosterol; vitamins A, $\mathrm{B}_{1}$, C and nicotinic acid; and $0.015 \%$ volatile oils (nalkanes and sesquiterpenes) [135].Trigonelline degraded to nicotinic acid and related pyridines during roasting is responsible for the flavor of the seed [124]. The importances of diosgenin in the synthesis of oral 
contraceptives and sex hormones have been documented [125]. Numerous studies have been carried out to reveal the therapeutic potential of fenugreek in various pathological conditions such as diabetes mellitus, cancer, hypertension, cataract, gastric disorders and obesity [126,127,128,129,130,131]. In a study [132], found that methyl fatty acid esters shows significant variation among genotypes and grinding methods.

\section{Medicinal and Pharmacological Properties}

a) Diabetes Mellitus: The fenugreek alkaloidal extract prevent the increased blood glucose level reduced lipid profile to almost normal and showed antioxidant effect on the tissues of liver and kidney in experimental rats [133]. Further, fenugreek powder treatment in patients suffering from mild Non-insulin dependent diabetes mellitus produced marked reduction in blood sugar and serum triglycerides and total cholesterol [127]. It has been documented from various studies that saponins and diosgenin present in fenugreek are responsible for hypolipidemic and anti-diabetic action on hypercholestrolaemic rats [134].It has been observed that supplementation of diet with fenugreek leaves and seeds in hyperglycemic rats prevented the increased levels of glucose by stimulating the process of glycolysis and inhibiting glucuneogenesis via stimulating enzymes such as hexokinase and inhibiting enzymes such as glucose 6-phosphatase and fructose 1, 6-biphosphatase and subsequently increasing the secretion of insulin [135]. It has been reported that the active principle present in water extract of fenugreek seeds in subdiabetic and overtly diabetic rabbits stimulated insulin synthesis and secretion from the beta pancreatic cells of langerhans and increased the sensitivity of tissues to available insulin [136]. The soluble dietary fibre fraction known as galactomannan present in endosperm of fenugreek seeds, has shown to reduce postprandial elevation in blood glucose level of Type 2 model diabetic rats by delaying the digestion of sucrose.

b) Cancer: The effect of fenugreek seeds observed in induced breast cancer in rats [136,137], Further, the ethanolic extract of fenugreek showed antineoplastic effect on the growth of breast cancer cells by reducing cell viability, inducing early apoptotic changes, declining the mitochondrial membrane potential and degrading cellular DNA into fragments [138]. Moreover, an in vitro study revealed that diosgenin inhibited cell growth and induced apoptosis in the human colon cancer cell [139]. Further, reducing the levels of cholesterol and decreasing the expression of phospholipase $\mathrm{A}$ and $\mathrm{C}$ are responsible for prevention of tumor formation and improving the histological features. Its estrogenic property can be employed as anticancer and in hormone replacement therapy in which further studies are warranted.

c) Antioxidant: It has been documented in various studies that fenugreek bears potential of a powerful antioxidant in which the presences of flavonoids and polyphenols have been found to be responsible for the same [140]. The exposure of polyphenol rich extract offenugreek seeds which showed protective effects against hydrogen peroxide induced oxidation by protecting the erythrocytes from haemolysis and lipid peroxidation in a dose dependent manner [141]. Further, fenugreek administration to diabetic animals showed a reversal of the disturbed antioxidant levels of enzymes such as catalase, superoxide dismutase and glutathione peroxidase and peroxidative damage in the tissues of heart and kidney [142]. Supplementation of fenugreek seed powder to diabetic rats normalized the alterations in lipid peroxidation and oxidative stress [143]. In different green plant parts of fenugreek, maximum phenolic content and flavonoid contents were observed in distilled water extract followed by methanol and ethyl acetate. Cryogrinding techniques improves its antioxidant activity and retains medicinal properties by prevent molecules which good for human health [144]. The ability of fenugreek as functional food tested by determining the lipid peroxidation (LPO), and cycloooxygenase enzyme (COX) inhibitory activities of hexane, ethyl acetate, methanolic and water extracts. The extracts inhibited the LPO by $50-95 \%$, CCOX- 1 by $6-87 \%$ and COX-2 by $36-70 \%$ respectively [145].

d) Ulcer: It is worth noting that fenugreek protects ulcerformation in rats via decreasing gastric volume, ulcer index value, total acidity, lesion formation and curative ratio by markedly increasing the level of mucus secretion [129]. It may be due to the cytoprotective action offenugreek can be attributed to the presence of flavonoids; which exert their antiulcer effect.

e) Inflammation: Fenugreek reduced paw edema in rats, the presence of alkaloids in extract of fenugreek has been reported to produce anti-inflammatory property by reducing edema in rats [146]. Fenugreek has been reported to accelerate the process of wound healing via its antioxidant potential in rats injured in the posterior neck area [147]. It may be suggested that the presence of diosgenin in fenugreek plays a key role in producing antiinflammatory action probably by acting the precursor of various steroid hormones such as progesterone and cortisone; which have set a benchmark for preventing inflammation in various pathological conditions.

f) Obesity: The beneficial effects of fenugreek fiber was studied in healthy obese subjects which demonstrated that fenugreek administration showed marked increase in satiety and fullness and marked fall in hunger and prospective food consumption with reduced energy intake using visual analog scale which may act supportive for treating acute obesity patients. Galactomannan and unpalatably of the fenugreek fiber is assumed to be responsible for promoting satiety by decreasing the rates of gastric emptying and decreased energy intake respectively [130].

g) Hypertension: It has been elucidated that the administration of fenugreek methanol extract and methanol fraction to rats shows antihypertensive. The essential oil obtained from fenugreek in combination with other essential oils has been employed to reduce systolic blood pressure 
in spontaneously hypertensive rat [148]. The aqueous and benzene extract of fenugreek has been found to show diuretic activity in rats; which can be employed to treat hypertension [149].

h) Other Disorders: Administration of fenugreek seed extract to both mice and rats revealed its effect on thyroid hormone that fenugreek inhibits the synthesis of tri-iodothyronine concentration estimated by decrease in serum tri-iodothyronine concentration and $\mathrm{T} 3 / \mathrm{T} 4$ ratio and consequently increased thyroxine levels which can be mediated through fenugreek-induced hypoglycaemia [150]. It has been reported that oral treatment with fenugreek reduced the quantity of calcium oxalate deposited in the kidneys induced by $3 \%$ glycolic acid in rats; which further supports its use in Saudi folk medicine [151]. Fenugreek showed anti-cataract property in sodium selenite-induced cataract in rats by restoring the levels of glutathione and other antioxidant enzymes such as superoxide dismutase, catalase, etc, in the lens and inhibiting the lipid peroxidation [131]. The alkaloidal, ethanol and butanol extract of fenugreek has been documented to possess anti plasmodial activity against in vitro culture of chloroquine sensitive and resistant Plasmodium falciparum [152].

i) Nigella (Nigella sativa L.): Among various medicinal plants, Nigella sativa belongs to family Ranunculaceae, is emerging as a miracle herb with a rich historical and religious background. Many researches reported its wide spectrum of pharmacological potential. Nigella is considered to be originated in Southwest Asia, Southern Europe and North Africa. It is cultivated in many countries maily in the world like India followed by Pakistan, Middle Eastern Mediterranean region, Southern Europe, Syria, Turkey, Saudi Arabia. The seeds of nigella and their oil have been widely used for centuries in the treatment of various ailments throughout the world. It is an important drug in the Indian traditional system of medicine like Unani and Ayurveda [153, 154].

Nigella is considered one of the important healing medicines for all diseases except death in one of the Prophetic hadith. It is also mentioned for use on regular basis in Tibb-e-Nabwi (Prophetic Medicine) [154]. Nigella possess wide spectrum of activities viz. as antidiabetic, diuretic, antihypertensive, anticancer and analgesic, immunomodulatory, antimicrobial, anthelmintics, analgesics and anti-inflammatory, spasmolytic, gastroprotective, bronchodilator, hepatoprotective, renal protective and antioxidant properties. The seeds of nigella are widely used in the treatment of various diseases like asthma, bronchitis, diarrhea, rheumatism and skin disorders. Nigella is also used as digestive, liver tonic, appetite stimulant, antidiarrheal, emmenagogue, to increase milk production in nursing mothers to fight parasitic infections and to support immune system [155], [156]. Therapeutic properties of this herb are due to the presence of thymoquinone compound present in its essential oil. Nigella seeds are also used in food like flavoring additive in the breads and pickles because it has very low level of toxicity [157].

j) Chemical composition of nigella seeds: Many active compounds have been identified, isolated and reported in different varieties of nigella seeds. The important active compounds are thymoquinone (30\%-48\%), , p-cymene (7\%$15 \%)$, carvacrol (6\%-12\%), 4-terpineol (2\%-7\%), t-anethol (1\%$4 \%)$, sesquiterpene longifolene (1\%-8\%) thymohydroquinone $(1.17 \%-2.31 \%), \alpha$-pinene and thymol etc. Its seeds also contain two different types of alkaloids; i.e. isoquinoline alkaloids e.g. nigellicimine and indazole ring bearing alkaloids or nigellicimine-N-oxide and pyrazol alkaloids which include nigellicine and nigellidine. Besides, Nigella seeds also contain alpha-hederin, a water soluble pentacyclic triterpene and saponin, an important anticancer agent $[158,159]$.

Some other compounds e.g. carvone, limonene, citronellol were also found in trace amounts. Most of the pharmacological properties of Nigella sativa are mainly attributed to quinine constituents, of which TQ is the most abundant. On storage, TQ yields dithymoquinone and higher oligocondensation products. The seeds of Nigella sativa contain protein (26.7\%), fat (28.5\%), carbohydrates (24.9\%), crude fibre $(8.4 \%)$ and total ash (4.8\%). The seeds are also containing good amount of various vitamins and minerals like $\mathrm{Cu}, \mathrm{P}, \mathrm{Zn}$ and $\mathrm{Fe}$ etc. The seeds contain carotene which is converted by the liver to vitamin A. Root and shoot are reported to contain vanillic acid $[160,161]$. Nigella seeds also reported to contain fatty oils rich in unsaturated fatty acids, mainly linoleic acid (50-60\%), oleic acid (20\%), dihomolinoleic acid (10\%) and eicodadienoic acid (3\%). Palmitic, stearic acid (saturated fatty acids) (30\% or less), $\alpha$-sitosterol is a major sterol, which accounts for $44 \%$ and $54 \%$ of the total sterols in Tunisian and Iranian varieties of nigella seed oils respectively, followed by stigmasterol (6.57-20.92\% of total sterols) $[162,163]$. Some other reports of chemical components includes nigellone, campesterol, cholesterol, citrostadienol, cycloeucalenol, gramisterol, lophenol, obtusifoliol, stigmastanol, avenasterol-5-ene, avenasterol-7-ene, stigmasterol-7-ene, $\beta$-amyrin, butyro-spermol, cycloartenol, 24-methylene-cycloartanol, taraxerol, tirucallol, 3 -0-[ $\beta$-D-xylopyranosyl $(1 \rightarrow 3)$ - $\alpha$-L-rhamnopyranosyl $(1 \rightarrow 2)$ $\alpha$-L-arabino-pyranosyl]-28-0-[ $\alpha$-L-rhamnopyranosyl( $1 \rightarrow 4$ )$\beta$-D-glucopyranosyl $(1 \rightarrow 6)-\beta$-D-gluco-pyranosyl] hederagenin, volatile oil (0.5-1.6\%), fatty oil (35.6-41.6\%), oleic acid, esters of unsaturated fatty acids with $\mathrm{C} 15$ and higher terpenoids, esters of dehydrostearic and linoleic acid, aliphatic alcohol, $\beta$-unsaturated hydroxy ketone, hederagenin glycoside, melanthin, melanthigenin, bitter principle, tannin, resin, protein, reducing sugar, glycosidal saponin, $3-0-[\beta$-D-xylopyranosyl- $(1 \rightarrow 2)$ - $\alpha$-L-rhamno-pyranosyl$(1 \rightarrow 2)$ - $\beta$-D-glucopyranosyl]-11-methoxy-16,23-dihydroxy28-methy-lolean-12 enoate, stigma-5, 22-dien-3- $\beta$-D-glucopyranoside, cycloart-23-methyl-7, 20, 22-triene-3 $\beta, 25$-diol, nigellidine-4-O-sulfite, $\mathrm{N}$. mines A3, A4, A5, C, N. mines A1, A2, B1, and B2 [164,165].

k) Traditional uses of folk remedies: Nigella has been traditionally used for the treatment of a variety of disorders, diseases and conditions pertaining to respiratory system, digestive tract, kidney and liver function, cardio vascular system and immune system support, as well as for general well-being [153,155]. Avicenna refers to black seeds in the "The Canon of Medicine", as seeds stimulate the body's energy and helps recovery from fatigue and dispiritedness. Nigella seeds 
and their oil have a long history of folklore usage in Indian and Arabian civilization as food and medicine [166,167]. The seeds have been traditionally used in Southeast Asian and the Middle East countries for the treatment of several diseases and ailments including asthma, bronchitis, rheumatism and related inflammatory diseases. Its many uses have earned Nigella the Arabic approbation 'Habbatul barakah', meaning the seed of blessing. Tincture prepared from nigella seeds is useful in the treatment of worms and skin eruptions. Externally the oil is used as an antiseptic and local anesthetic. Roasted black seeds are given internally to stop the vomiting [153, 168-170].

\section{Medicinal and Pharmacological Properties}

a) Antimicrobialactivity: Bacteria like gram-positive and gram-negative can be suppressed by nigella essential oil. It exhibited strong antimicrobial activity against Salmonella typhi, Pseudomonas aeruginosa and others. Comparatively higher sensitivity against gram-positive bacteria Staphylococcus aureus and Vibrio cholera was found to be stronger than gram negative bacteria. Staphylococcusaureus, Staphylococcuspyogenes and Staphylococcusviridans are more susceptible to Nigella sativa. The dried seeds of $N$. sativa exhibited bactericidal activity against Pseudomonas aeruginosa [171,172]. The activity of the volatile oil against drug - resistants trains of Shigellaspp, Vibriocholera and Escherichia coliwas found to have a synergistic action with streptomycin and gentamycin. A clear inhibition of the growth of Staphylococcusaureus was observed by concentration of $300 \mathrm{mg} / \mathrm{ml}$. The positive inhibition may beat tributed to the two important active in gredients of Nigellasativa, Thymoquinone (TQ) andmelanin. TQ exhibited a significant bactericidal activity against various human pathogenic bacteria especially gram positive cocci, i.e. Staphylococcus aureus and Staphylococcus epidermidis [173177].

b) Antifungal activity: Methanolic extracts of Nigella have the strongest antifungal effect followed by the chloroform extracts against different strains of Candida albicans. An intravenous inoculum of Candida albicans produced colonies of the organism in the liver, spleen and kidneys. Treatment of mice with the plant extract $24 \mathrm{~h}$ after the inoculation caused a considerable inhibitory effect on the growth of the organism in all organs studied. Khan et al. in 2003 reported that the aqueous extract of Nigella seeds exhibits inhibitory effect against candidiasis in mice. A 5-fold decrease in Candida in kidneys, 8-fold in liver and 11-fold in spleen was observed in the groups of animals post-treated with the plant extract. These findings were also confirmed by Histopathological examination of the respective organs [178]. The anti-yeast activity of the black cumin seed quinines, dithymoquinone, thymohydroquinone, and TQ were evaluated in vitro with a broth microdilution method against six dairy spoilage yeast species. It was found that Antifungal effects of the quinones were compared with those of preservatives commonly used in milk products (calcium propionate, natamycin, and potassium sorbate) at two $\mathrm{pH}$ levels (4.0 and 5.5), while thymohydroquinone and
TQ possessed significant antiyeast activity [179]. Two novel antifungal defensins named Ns-D1 and Ns-D2, were isolated from seeds of Nigella and sequenced. The Ns-D1 and NsD2 defensins displayed strong divergent antifungal activity towards a number of phytopathogenic fungi [180].

c) Anti-schistosomiasis activity: The effect of NSO against the liver damage induced by Schistosoma mansoni (S. mansoni) infection in mice was studied by Mahmoud et al. When the NSO was given alone, it reduced the number of S. mansoni worms in the liver and decreased the total number of ova deposited in both the liver and the intestine. These results suggest that NSO may play a role against the alterations caused by $S$. mansoni infection [181]. Results of in vitro testing of N. Sativa seeds against Schistosoma mansoni, miracidia, cercariae, and adult worms indicate its strong biocidal effects against all stages of the parasite and an inhibitory effect on egg-laying of adult female worms.

d) Antioxidant activity: Treating broiler chicks with black seeds for 6 weeks prevented the liver from oxidative stress by increasing the activities of enzymes such as myeloperoxidase, glutathione-S-transferase, catalase, adenosine deaminase, myeloperoxidaseand by decreasing hepatic lipid peroxidation. The crude methanolic extract of black cumin seed cake was found to show significant antioxidant properties under in vitro systems. The thymoquinone pretreatment restored the increased level of malonyl dialdehyde and conjugated diene levels [182-187].

e) Antidiabeticactivity: Significanthypoglycaemic activity was reported. Antihyperglycemic effects of Nigella seed extract are attributed to a combination of the rapeutically relevant insulinotropic and insulin-like properties [188-190]. Polyherbal formulation kalonji sugar powder) has antidiabetic effect. It reverses the abnormal lipid profile observed in diabetic animals. There fore the water extract of this formulation is useful in maintaining healthy glucose levels and cholesterol levels [191]. Combination of $\alpha$-lipoicacid, L-carnitine and Nigella may contribute significantly in improvement of the carbohydrate metabolism in diabetic rats, thus increasing the rate of success in management of diabetics. It was also demonstrated that in vivo treatment with Nigella sativa seed extract exerts an insulin - sensitizing action by enhancing ACC phosphorylation, a major component of the insulin - independent AMPK signalling path way and by enhancing muscleGlut4content [192-195].

f) Anticancerous activity: Treatment of hamsters with Nigella volatile oil did not induce any dysplastic alterations or carcinomas in the cheek pouches of the animals [196]. Furthermore, chemical treatment of rats with 1, 2-dimethylhydrazine-induced colon cancer in the post initiation stage but daily treatment with $N$. sativa volatile oil for 14 weeks induced significant reductions in the colonic lesions via suppression of the cell proliferation in the colonic mucosa [197]. The treatment did not induce any harmful effects in the blood or urine parameters and no pathological changes in the various vital 
body organs. Furthermore, exposure of various human cancer cell lines to the volatile oil in concentrations of $120-380 \mu \mathrm{g} / \mathrm{ml}$ induced significant death of the cells showing clear cytotoxic effect [198-204].

g) Anti-inflammatory and analgesic activity: The chronic inflammatory disorders, asthma and arthritis involve a variety of inflammatory mediators and pathways. Nigella fixed oil and thymoquinone were found to inhibit membrane lipid peroxidation and eicosanoid generation in leucocytes, significantly reduced rat paw oedema and granulomapouch weight. Nigellonein low concentration is effective in inhibiting the histamine release from the mast cells, which supports an antiasth maticrole for theplant [205]. Osteoporosis has been linked to oxidative stress and inflammation. The studies on the anti-osteoporotic effects of Nigella and TQ were carried out. It was revealed that Nigella and TQ were shown to inhibit inflammatory cytokines such as interleukin-1 and 6 and the transcription factor, nuclear factor $\kappa \mathrm{B}$. Both NS and TQ have shown potential as anti-osteoporotic agent [206]. The antiallergic effects of Nigella seed components could be attributed to allergic rhinitis. Moreover, Nigella should be considered for treating allergic rhinitis when the effects of other anti-allergic drugs need to be avoided [207].

h) Immunomodulatory activity: The potential immunomodulatory effects of Nigella were investigated in light of splenocyte proliferation, macrophage function, and NK anti-tumor activity using BLAB/c and C57/BL6 primary cells. Finally, experimental evidence indicates that the aqueous extract of $N$. sativa significantly enhances NK cytotoxic activity against YAC-1 tumor cells, suggesting that the documented anti-tumor effects of $N$. sativa may be, at least in part, attributed to its ability to serve as a stimulant of NK anti-tumor activity. It was anticipated that $N$. Sativa ingredients may be employed as effective therapeutic agents in the regulation of diverse immune reactions implicated in various conditions and diseases such as cancer [208]. Treatment (intraperitoneal injection) with five doses of methanolic extract for Black seed was found to enhance the total white blood cells count [up to $1.2 \times 10^{4}$ cells $/ \mathrm{mm}^{3}$ ]. Bone marrow cellularity also increased significantly $(P<0.01)$ after the administration of the Black seed extract. Spleen weight of the black seed treated groups was significantly increased $(P<0.01)$. These results indicated that the Nigella sativa seeds could be considered as a potential immunosuppressive cytotoxic agent [209]. Nigella sativa oil is a promising natural radioprotective agent against immunosuppressive and oxidative effects of ionizing radiation [210]. Daily oral administration of Nigella sativa oil to rats before whole body gamma irradiation resulted in significant reversal of reduction of hemolysin antibodies titers [211].

i) Gastro-protective activity: The anti-ulcer potential of Nigella sativa aqueous suspension on experimentally induced gastric ulcers and basal gastric secretion in rats was examined to rationalize its use by herbal and Unani medicine practitioners. Acute gastric ulceration was produced by various noxious chemicals (80\% ethanol, $0.2 \mathrm{~mol} / \mathrm{L} \mathrm{NaOH}, 25 \% \mathrm{NaCl}$ and indomethacin) in Wistar albino rats. Anti-secretory studies were undertaken in a separate group of rats. The anti-ulcer effect of Nigella sativa is possibly prostaglandin-mediated and/or through its antioxidant and anti-secretory activities [212]. Nigella sativa prevents alcohol induced increase in lipid peroxidation (i.e. thiobarbituric acid reactive substances) and reduced gastric GSH content, enzyme activities of gastric SOD, GSH-S-Transferase [213]. These findings suggest that TQ could serve as a potential therapeutic agent for the treatment of patients with inflammatory bowel disease [214]. Decoction of nigella with rock salt is given for relief in dyspepsia and stomachache [89].

j) Hepato-protective activity: It is reported that Nigella sativa $(0.2 \mathrm{~mL} / \mathrm{kg})$ intraperitoneally relieves the deleterious effects of ischemia reperfusion injury on liver. Biochemical parameters like the serum aspartate aminotransferase, alanine aminotransferase lactate dehydrogenase levels and total antioxidant capacity (TAC), CAT, total oxidative status (TOS), oxidative stress index (OSI) and MPO were determined in hepatic tissue in rats with hepatic ischemia. Results suggested that Nigella sativa treatment protects the rat liver against hepatic ischemia reperfusion injury [215]. Nigella sativa administration protects hepatic tissue from deleterious effects of toxic metals such as lead, and attenuates hepatic lipid peroxidation following exposure to chemicals such as carbon tetrachloride [216].

k) Nephroprotectiveactivity: The nephroprotective effect of vitamin C and Nigella sativa oil was observed against gentamicin (GM) associated nephrotoxicity in rabbits. Serum creatinine, blood urea nitrogen, and antioxidant activity were measured as indicators of nephrotoxicity for all the groups of rabbits. It was revealed that vitamin $\mathrm{C}$ and Nigella sativa oil both had nephroprotective effect as they lowered the values of serum creatinine, blood urea nitrogen, and antioxidant activity as compared to GM control group values. When these two antioxidants were given as combination, they proved to have synergistic nephro protective effect [217- 219].

I) Pulmonary-protective activity and anti-asthmatic effects: Nigellone and high concentrations of TQ had a concentration-dependent inhibitory effect on the trachea when being contracted by the depolarizing effect of $\mathrm{Ba}^{2+}$. The trachea contractions induced by leukotriene-d (4) LT4 were inhibited by nigellone and by TQ. It was concluded that nigellone possesses an antispasmodic effect and an increase in mucociliary clearance but TQ do not have such effects. Therefore, it is suggested that nigellone but not TQ may be useful in treatment of different respiratory diseases [220]. It showed relaxant effect of most fractions from Nigella sativa on tracheal chains of guinea pigs which was more potent for methanol and dichloromethane fractions [221].

The possible beneficial effects of the seeds of Nigella sativa on experimental lung injury in male Wistar rats after pulmonary 
aspiration of different materials were investigated. Results showed that Nigella sativa treatment inhibits the inflammatory pulmonary responses, reducing significantly $(P<0.05)$ peribronchial inflammatory cell infiltration, alveolar septal infiltration, alveolar edema, alveolar exudate, alveolar macrophages, interstitial fibrosis, granuloma and necrosis formation in different pulmonary aspiration models. Data indicated a significant reduction in the activity of inducible nitric oxide synthase and a rise in surfactant protein D in lung tissue of different pulmonary aspiration models after Nigella sativa therapy. It was concluded that Nigella sativa treatment might be beneficial in lung injury and have potential clinical use [222]. A study showed that Nigella sativa has a relatively potent antiasthmatic effect on asthmatic airways. However, the effects of boiled extract of this plant on most measured PFTs were less than those of theophylline at concentrations used [223].

j) Testicular-protective activity: The protective role of TQ on testicular toxicity of methotrexate on male C57BL/ 6 mice (6 weeks old, $20 \pm 2 \mathrm{~g}$ ) was investigated. TQ treatment decreased TAC and prevented the increase in the myeloperoxidase activity. Light microscopy showed in mice that receiving methotrexate resulted in interstitial space dilatation, edema, severe disruption of the seminiferous epithelium and reduced diameter of the seminiferous tubules. Administration of TQ reversed histological changes of methotrexate significantly. It was suggested that TQ use may decrease the destructive effects of methotrexate on testicular tissue of patients using this agent [224].

k) Neuro pharmacolgical activities: The aqueous and methanol extracts of defatted Nigella sativa seeds were shown to possess a potent central nervous system and analgesic activities, especially depressant action in the case of the methanolic extract. The neuroprotective effects of both the extracts of Nigella sativa in cerebralischemia were observed. The neuroprotective effects could be due to its antioxidant, free radical scavenging, and anti-inflammatory properties [225227].

I) Anticonvulsant activity: The antiepileptic effects of aqueous extract, fixed oil, volatile oil of $N$. sativa seeds and its major constituents i.e. TQ, $\alpha$-pinene and p-cymene against PTZ and maximal electroshock (MES)-induced convulsions were investigated. The potential of these constituents to induce minimal neurological deficit (MND) was also evaluated by using chimney test. All of the Nigella sativa seed constituents protected mice effectively against PTZ-induced convulsions except fixed oil. The antiepileptic activity of the volatile oil in this model maybe attributed mainly to its content of TQ and p-cymene and to a lesser extent, $\alpha$-pinene. [228].

m) Contraceptive and anti-fertility activity: Oral administration of Hexane extract of Nigella sativa L. seeds prevented pregnancy in Sprague-Dawley rats at a dose of 2 $\mathrm{g} / \mathrm{kg}$ daily on day's 1-10 postcoitum. While column fractions and sub-fractions of Hexane extract of Nigella sativa L. seeds also showed significant anti-fertility activity. At contraceptive dose, the active hexane extract exhibited only mild uterotrophic activity comparable almost to $0.002 \mathrm{mg} / \mathrm{kg}$ dose of 17 varies; is directly proportional to-Ethinylestradiol, but was devoid of any estrogenicity in the immature rat bioassay [229]. The ethanolic extract of $N$. sativa seeds was found to possess an anti-fertility activity in male rats which might be due to inherent estrogenic activity of Nigellasativa [230].

n) Antioxytocic activity: The antioxytocic properties of Nigella sativa were reported in some preliminary studies. $N$. sativa seeds inhibit the uterine smooth muscle contraction induced by oxytocin stimulation.The volatile oil of $N$. sativa seeds inhibited the spontaneous movements of rat and guinea piguterine smooth muscle and also the contractions induced by oxytocin stimulation which suggest the antioxytocic potential of Nigella sativa seeds oil [231].

o) Toxicological studies: Many toxicological studies have been carried out on Nigella sativa seeds. No toxic effects were reported when nigella fixed oil was given to mice via the stomach in a study. In an another chronic toxicity study rats treated daily with an oral dose for 3 months caused no changes in key hepatic enzyme levels particularly alanine-aminotranferase, aspartate-aminotransferase, and gammaglutamyl-transferase. Moreover, the histopathological results also showed to be normal for the tissues of heart, liver, kidneys and pancreas $\mathrm{LD}_{50}$ values of fixed oil of $N$. sativa obtained by single doses orally and intraperitoneally in mice, were reported to be 26.231.6 and 1.86-2.26, respectively. The low toxicity of nigella fixed oil, evidenced by high $\mathrm{LD}_{50}$ values, organ integrity and key hepatic enzyme stability, suggests a wide margin of safety for therapeutic doses of Nigella fixed oil [232]. In another study, the $\mathrm{LD}_{50}$ of TQ was found to be $104.7 \mathrm{mg} / \mathrm{kg}$ (89.7-119.7) and 870.9 $\mathrm{mg} / \mathrm{kg}$ (647.1-1 094.8) after intra-peritoneal injection and oral ingestion, respectively. However, $\mathrm{LD}_{50}$ in rats was found to be $57.5 \mathrm{mg} / \mathrm{kg}$ (45.6-69.4) and 794.3 mg/kg (469.8-1 118.8) after intra-peritoneal injection and oral ingestion, respectively. The $\mathrm{LD}_{50}$ values shown here after intra-peritoneal injection and oral ingestion are 10-15 times and 100-150 times greater than doses of TQ reported for its anti-oxidant, anti-inflammatory, and anti-cancer effects [156,233].

p) Drugs-nigella interaction: There is a possibility that Nigella sativa may interact with co-administered drugs and affect their intestinal availability and pharmacological effect. In vitro studies have shown that $N$. sativa extracts inhibit cDNA-expressed human cytochrome P-450 3A4, 2C9, 3A5 and 3A7-mediated metabolism of marker substrates therefore may affect and/or inhibit the metabolism of a wide range of drugs (). Further, the effect of Nigella sativa on bioavailability of amoxicillin was investigated in everted rat intestinal sacs. The in vitro studies both with methanol and hexane extracts of Nigella increased the permeation of amoxicillin significantly $(P<0.001)$ as compared to control. Permeation was also found to be significantly higher for the hexane extract $(P<0.001)$ in comparison to methanol extract at the same dose levels. in vivo experiments revealed that $\mathrm{Cmax}$ of amoxicillin in rat 
plasma when administered orally alone and in combination with hexane extract increased correspondingly from $4138.251 \pm 156.930$ to $5995.045 \pm 196.280 \mathrm{ng} / \mathrm{mL}$ while as AUC $0 \rightarrow \mathrm{t}$ increased from $8890.40 \pm 143.33$ to $13483.46 \pm 152.45$ $\mathrm{ng} / \mathrm{mL} / \mathrm{h}$. Nigella enhanced amoxicillin availability in both in vivo and in vitro studies [234].

\section{Conclusion}

Ajwain seed possesses stimulant, antispasmodic and carminative properties and is used traditionally as an important remedial agent for flatulence, atonic dyspepsia, diarrhea, abdominal tumors, abdominal pains, piles, and bronchial problems, lack of appetite, galactogogue, asthma and amenorrhea. Medicinally, it has been proven to possess various pharmacological activities like antifungal, antioxidant, antimicrobial, antinociceptive, cytotoxic, hypolipidemic, antihypertensive, antispasmodic, bronchodilating actions, antilithiasis, diuretic, abortifacient, antitussive, nematicidal, anthelmintic and antifilarial. Further, studies reveal the presence of various phytochemical constituents mainly carbohydrates, glycosides, saponins, phenolic compounds, volatile oil (thymol, $\gamma$-terpinene, para-cymene and $\alpha$ and $\beta$-pinene), protein, fat, fiber and mineral matter containing calcium, phosphorous, iron and nicotinic acid. These studies reveal that Trachyspermum ammiis a source of medicinally active compounds and have various pharmacological effects; hence, it is encouraging to find its new therapeutic uses.

Coriander volatile oil is rich in beneficial phytonutrients and the seeds have a health-supporting reputation that is high on the list of the healing spices and has been used as antispasmodic, carminative, stimulant, cytotoxic, lipolytic, fungicidal and stomachic compound. Coriander also possesses hypoglycemic, hypolipidemic, antibacterial, antimutagenic activity, insecticidal and aflatoxin controlling effects. Besides, coriander also possesses many other traditional health benefits. The healing properties of coriander can be attributed to its exceptional phyto-nutrient content. Considering these potentials, coriander biomolecules possess a tremendous future in the health-related industry. The different forms of cumin possess many remarkable health benefits, viz., anti-diabetic, antimicrobial, antiseptic, and antioxidant, inhibition of blood platelet aggregation etc. The flavanoids apigenin, luteolin, and their glycosides present in cumin are reported to be responsible for many of the biological activities of cumin. Cuminaldehyde, the major constituent of volatile oil, is responsible for the antimicrobial and anti-mutagenic properties. Spent residue from cumin has the potential as a new source of dietary fiber which can be utilized for incorporation into many food formulations.Dill has been used mainly for culinary and medicinal purposes for hundreds of years. The health benefits of dill include improvement in digestion, relief from insomnia, hiccups, dysentery, diarrhea, respiratory disorders, menstrual disorders, protects from bone degradation and various types of cancers.

It is also good for oral care and can be a powerful boost for immune system of human body. It is also used as an antiinflammatory, can a carminative substance. Fennel has been used as food and medicine with long history in central Europe and Mediterranean region as well as in China. It is also a flavor food with health value. Numerous compounds including trans-anethole, estragole, fenchone, sesquiterpenoids, coumarins and polyphenolics were isolated from this plant, most of which exhibited significant bioactivities. The fennel has potential beneficial therapeutic actions in the management of bacterial and fungal infections and colic pain. Both the fruit and whole plant of this plant might be the source of chemical and biological materials in future. For further utilization of this plant, systematic phytochemical and biological mechanic studies are needed.

Fenugreek has an extensive variety of actions which are likely to protect the human body against a variety of insults. Fenugreek has the potential to ameliorate diabetes mellitus exhibited by stimulating glycolytic enzymes, inhibiting gluconeogensis. Further, the exaggerated action of fenugreek in treating cancer has been demonstrated through various mechanisms such as induction of apoptosis, inhibition of cell proliferation and arachidonic acid pathway.

Increasing body of evidences suggests that oxidative stress plays a vital role in the induction and progression of various disorders such as atherosclerosis, Parkinson's disease, heart failure, myocardial infarction and Alzheimer's disease. But the promising antioxidant effect of fenugreek needs to be explored in these diseases. In spite of various pleiotropic actions of fenugreek on chronic disorders such as obesity, inflammation, hypertension and ulcers, the relevant clinical applications of fenugreek is still in the queue of thirst area of research. Therefore, more focused research on specific experimental models, human trials and an understanding the mechanism of action is necessary. Nigellasativa L., a common herb aceous seed spice of India and Middle East, was identified by many researchers to have as spectrum of pharmacological and nutraceutical potentials. The seeds of nigella and it soil were widely used for centuries in the treatment of various ailments throughout the world. It is an important drug in the Indian traditional system of medicine. It is established that most of the potential and fruitful activities are inbuilt in its volatile oil and protein components. Most of the therapeutic properties of this herb are due to the presence of thymoquinone and its isomers which are the major active chemical component of the essential oil.

Nigella seeds are also used in food as flavouring, additive in the breads and pickles because it has very low level of toxicity. Mechanism of actions of Nigella seed extract sand its constituents by which they exert their rapeutic effects needs to be further investigated and tested. Chemical modifications in the molecular structure of Thymoquinone, $\alpha$-Hederin and other constituents of nigella seeds could lead to prepare more effective and safer drugs for the treatment of wide variety of diseases in the future in suitable combinations. Moreover, further researches should focus and explore the specific cellular and molecular targets of various constituents of Nigella, particularly Thymoquinone. This review article is dedicated to all those researchers who are interested in focussing their research on this miracle herb and hope, this review 
article would help the min investigating and conducting further preclinical and clinical studies on the use of seed spices for the treatment of variety of diseases.

\section{References}

1. Retelny VS, Neuendorf A, Roth JL (2008) Nutrition protocols for the prevention of cardiovascular disease. Nutr Clin Pract 23(5): 468-476.

2. Zarraga IGE, Schwarz ER (2006) Impact of dietary patterns and interventions on cardiovascular health.Circulation 114: 961-973.

3. Tapsell LC, Hemphill I, Cobiac L, Patch CS, Sullivan DR, et al. (2006) Health benefits of herbs and spices: the past, the present, the future. Med JAust 185(4): S4-S24.

4. Vaidya AD, Devasagayam TPA (2007) Current status of herbal drugs in India: An overview. J Clin Biochem Nutr 41(1): 1-11.

5. Modak M, Dixit P, Londhe J, Ghaskadbi S, Devasagayam TPA (2007) Indian herbs and herbal drugs used for the treatment of diabetes. J Clin Biochem Nutr 40(3): 163-173.

6. Rathore SS, Saxena SN, Solanky S, Manasia PM, Saxena R, et al. (2012) Analysis of medicinally important compounds and anti oxidant activity in crude extract of fenugreek (Trigonella foenum-gracium L.) plant parts. In: National seminar "Harnessing SeedSpices for Better Socio Economic Well Being held on 6-7 January 2012 at DAV College, Ajmer 3(2): $1-12$.

7. Rathore SS, Saxena SN (2012) Chemoinformatics: An efficient tool for exploiting high value compounds in seed spices. In Nationalseminar "Harnessing Seed Spices for Better Socio Economic Well Being held on 6-7 January 2012 at DAV College, Ajmer 3(2): 1-12.

8. Zachariah TJ, Safeer AL, Jayarajan K, Leela NK, Vipin TM, et al. (2010) Correlation of metabolites in the leaf and berries of selected black pepper varieties. ScientiaHorticulturae 123(3): 418-422.

9. Srinivasan K (2005) Plant foods in the management of diabetes mellitus: spices as beneficial antidiabetic food adjuncts. Int J Food Sci Nutr 56(6): 399-414.

10. Kelly GS (2000) Insulin resistance: lifestyle and nutritional interventions. Altern Med Rev 5(2): 109-132.

11. Mashour NH, Lin GI, Frishman WH (1998) Herbal medicine for the treatment of cardiovascular disease. Clinical consideration. Arch Intern Med 158(20): 2225-2234.

12. Talhouk RS, Karam C, Fostok S, El-Jouni W, Barbour EK (2007) Antiinflammatory bioactivities in plant extracts. J Med Food 10(1): 1-10.

13. Davidson A, Jaine $T$ (2014) The Oxford Companion to Food. In: Davidson A, Jaine T(Eds.) Oxford University Press, USA pp. 921.

14. Singh G, Maurya S, Catalan C, de Lampasona MP (2004) Chemical constituents, antifungal and antioxidative effects of ajwain essential oil and its acetone extract. J Agric Food Chem 52(11): 3292-3296.

15. Christie PJ, Atmakuri K, Krishnamoorthy V, Jakubowski S, Cascales E (2005) Biogenesis, architecture and function of bacterial Type IV secretion systems. Annu Rev Microbiol 59: 451-485.

16. Chatterjee SN, Das J (1967) Electron microscopic observations on the excretion of cell-wall terial by Vibrio cholerae. J. Gen. Microbiol 49(1): $1-11$.

17. Maton A (1993) Human Biology and Health. Pearson Prentice Hall, New Jersey, USA pp. 256.

18. Dusenbery DB (1996) Life at Small Scale: The Behavior of Microbes. Scientific American Library, New York, pp: 113-115.

19. Morsi NM (2000) Antimicrobial effect of crude extracts of Nigella sativa on multiple antibiotics-resistant bacteria. Acta Biochimica Polonica 49(1): 63-74.
20. Nagalakshmi S, Shankaracharya NB, Naik JP, Rao LJM (2000) Studies on chemical and technological aspects of ajowan (Trachyspermum ammi (L.) syn. Carum copticum Hiern) seeds. J Food Sci Technol 37(3): 277-281.

21. Tsimidou M, Boskou D (1994) Antioxidant Activity of Essential Oils from the Plants of the Lamiaceae Family. In: Spices, Herbs and Edible Fungi, Charalambous, G (Eds.), the Netherlands pp: 273-284.

22. William Evans (2002) Trease, Evans Pharmacognosy ( $16^{\text {th }}$ Edn.), In William Evans Saunders, New York 258.

23. Menphini A, Pagiotti R, Capuccella M (1993) Antifungal activity of carvacrol chemotypes of winter savory harvested in Italy. Rivita Italiana EPPOS 4: 566-571.

24. Platel K, Srinivasan K (2001) Studies on the influence of dietary spices on food transit time in experimental rats. Nutr Res 21(9): 1309-1314.

25. Ramaswamy S, Sengottuvelu S, Sherief SH, Jaikumar S, Saravanan $\mathrm{R}$, et al. (2010) Gastroprotective activity of ethanolic extract of Trachyspermum ammi fruit. Int J Pharma Bio Sci 1(1): 1-15.

26. Gilani AH, Jabeen Q, Ghayur MN, Janbaz KH, Akhtar MS (2005) Studies on the antihypertensive, antispasmodic, bronchodilator and hepatoprotective activities of the Carum copticum seed extract. J Ethnopharmacol 98(1-2): 127-135.

27. Murthy PS, BBBorse, H Khanum, P Srinivas (2009) Inhibitory effects of Ajowan (Trachyspermum ammi) ethanolic extract on A. ochraceus growth and ochratoxin production. Turk J Biol 33: 211-217.

28. Hawrelak JA, T Cattley, SP Myers (2009) Essential oils in the treatment of intestinal dysbiosis: A preliminary in vitro study. Altern Med Rev 14(4): 380-384.

29. Caccioni DRL, M Guizzardi, DM Biondi, A Renda, G Ruberto (1998) Relationship between volatile components of citrus fruit essential oils and antimicrobial action on Penicillium digitatum and Penicillium italicum. Int J Food Microbiol 43(1-2): 73-79.

30. Saxena AP, KM Vyas (1986) Antimicrobial activity of seeds of some ethno-medicinal plants. J. Econ. Taxon. Bot 8: 291-299.

31. SinghDB, SP Singh, RC Gupta (1979) Antifungal effect of volatiles from seeds of some Umbelliferae. Trans Br Mycol Soc 73: 349-350.

32. Thangam C, R Dhananjayan (2003) Antiinflammatory potential of the seeds of Carum copticum linn. Indian J Pharmacol 35(6): 388-391.

33. Jabbar A, Z Iqbal, M.N Khan (2006) In vitro anthelmintic activity of Trachyspermum ammi seeds. Pharmacogn. Mag 2(6): 126-129.

34. Kong JO, SM Lee, YS Moon, SG Lee, YJ Ahn (2006) Nematicidal activity of plant essential oils against Bursaphelenchus xylophilus (Nematoda: Aphelenchoididae). J Asia-Pac Entomol 9(2): 173-178.

35. Park IK, J Kim, SG Lee, SC Shin (2007) Nematicidal activity of plant essential oils and components from ajowan (Trachyspermum ammi), allspice (Pimenta dioica) and litsea (Litsea cubeba) essential oils against pine wood nematode (Bursaphelenchus xylophilus). J Nematol 39(3): 275-279.

36. Bairwa R (2011) Medicinal uses of Trachyspermum ammi: A review Pharm Res 5(2): 247-258.

37. Boskabady MH, S Kiani, P Jandaghi, L Hasanzadeh (2005) Antitussive effect of Carum copticum in guinea pigs. J. Ethnopharmacol 97(1): 7982.

38. Srivastava KC (1988) Extract of a spice-Omum (Trachyspermum ammi)-shows antiaggregatory effects and alters arachidonic acid metabolism in human platelets. Prostaglandins Leukotrienes Essent. Fatty Acids 33(1): 1-6.

39. Javed IM, T Akhtar, MZ Khaliq, G Khan, M Muhammad (2002) Antihyperlipidaemic effect of Trachyspermum ammi (Ajwain) in 
rabbits. Proceedings of the 33rd All Pakistan Science Conference, December 25-28. 2002, Faisalabad p. 80-81.

40. Ahsan SK, M Tariq, AM Ageel, MA Al-Yahya, AH Shah (1989) Studies on some herbal drugs used in fracture healing. Int. J. Crude Drug Res 27(4): 235-239.

41. Kaur H (1998) Estrogenic activity of some herbal galactogogue constituents. Indian J. Anim. Nutr 15(3): 232-234.

42. Priestley CM, EM Williamson, KA Wafford, DB Sattelle (2003) Thymol, a constituent of thyme essential oil, is a positive allosteric modulator of human GABAA receptors and a homo-oligomeric GABA receptor from Drosophila melanogaster. Br. J. Pharmacol 140(8): 1363-1372.

43. Jabeen Q, Bashir S, Lyoussi B, Gilani A (2009) Coriander fruit exhibits gut modulatory, blood pressure lowering and diuretic activities. J Ethnopharmacol 122(1): 123-130.

44. Bajpai M, Mishra A, Prakash D (2005) Antioxidant and free radical scavenging activities of some leafy vegetables.Int J Food Sci Nutr 56(7): 473-481.

45. Swanston-Flatt S, Day C, Bailey C, Flatt P (1990) Traditional plant treatments for diabetes: Studies in normal and streptozotocin-diabetic mice. Diabetologia 33(8): 462-464.

46. Chithra V, Leelamma S (1997) Hypolipidemic effect of coriander seeds (Coriandrum sativum): mechanism of action. Plant Foods Hum Nutr 51(2): 167-172.

47. Aissaoui A, El-Hilaly J, Israili Z, Lyoussi B (2008) Acute diuretic effect of continuous intravenous infusion of an aqueous extract of Coriandrum sativum L. in anesthetized rats. J Ethnopharmacol 115(1): 89-95.

48. Eidi M, Eidi A, Saeidi A, Molanaei S, Sadeghiour A, et al. (2008) Effect of coriander seed (Coriandrum sativum L.) ethanol extract on insulin release from pancreatic beta cells in streptozotocin-induced diabetic rats. Phytother Res 23(3): 404-406.

49. Suliman S, Elmahdi B, Abuelgasim A (2008) The effect of feeding Coriandrum sativum fruits powder on the plasma lipids profile in cholesterol-fed rats. Res J Ani \& Vet Sci 3: 24-28.

50. Purseglove JW, Brown EG, Green CL, Robbins SRJ (1981) Spices Vol II. Longman,London and New York, USA 2: 736-88.

51. Baratta MT, Dorman HJD, Deans SG, Biondi, DM, Ruberto G (1998) Chemical composition, antimicrobial and antioxidative activity of laurel, sage, rosemary, oregano and coriander essential oils. J Ess Oil Res 10(6): 618- 627.

52. Selvan MT (2003) Role of spices in medicine. Indian Journal Arecanut Spices Med Plants 5:129-133.

53. Nalini N, Sabitha K, Viswanathan P, Menon VP (1998) Influence of spices on the bacterial (enzyme) activity in experimental colon cancer. J Ethnopharmacol 62(1): 15-24.

54. Rathore SS, Saxena SN, Saxena R (2011) Effect of cryogenic grinding on medicinally important compounds and antioxidant properties of seed extract of coriander (Coriandrum sativum L.) genotypes. In National seminar on "Emergingtrends in Spice Processing and its Impact on Rural Economy" held at CTAE, Udaipur on 17-18

55. Ertas ON, Guler T, Cftc M, Dalklc B, Ylmaz O (2005) The effect of a dietary supplement coriander seeds on the fatty acid composition of breast muscle in Japanese quail. Revue-de-MédecineVétérinaire 156(10): 514-518.

56. Basilico MZ, Basilico JC (1999) Inhibitory effects of some spice essential oils on Aspergillus ochraceus NRRL 3174 growth and ochratoxin A production. Lett Appl Microbiol 29(4): 238-241.

57. Meena MR, Sethi V (1994) Antimicrobial activity of essential oils from spices. J Food SciTechnol 31: 68-70.

58. Shaath NA, Azzo NR (1993) Essential oil of Egypt. In: G. Charalambous (Edn): Food FlavorIngredients and Composition Charalambous, G, Ed., Elsevier, Amsterdam pp. 591-603.
59. Borges P, Pino J (1993) The isolation of volatile oil from cumin seeds by steam distillation. DieNahurung 37: 123-126.

60. Lee $H$ (2005) Cuminaldehyde: aldose reductase and $\alpha$-glucosidase inhibitor derived from Cuminum cyminum L. seeds. J Agric Food Chem 53(7): 2446-2450.

61. Roman-Ramos R, Flores-Saenz J, Alarcon-Aguilar FJ (1995) Antihyperglycaemic effect of some edible plants. J Ethnopharmacol 48(1): 25-32.

62. Dhandapani S, Subramanian V, Rajagopal S, Namasivayam N (2002) Hypolipidemic effect of Cuminumcyminum L. on alloxan-induced diabetic rats. Pharmacol Res 46(3): 251-255.

63. Willatgamuwa S, Patel K, Saraswati G, Srinivasan K (1998) Antidiabetic influence of dietary cumin seeds (Cuminum cyminum) in streptozotocin-induced diabetic rats. Nutr Res 18(1): 131-142.

64. Leung AY (1980) Encyclopedia of Common Natural Ingredients used in Foods, Drugs and Cosmetics, John Wiley, Hoboken, NJ 810.

65. Krishnakantha TP, Lokesh BR (1993) Scanvenging of superoxide anions by spice principles. Indian J Biochem Biophys30(2): 133 -134.

66. Srivastava KC (1989) Extracts from two frequently consumed spicescumin (Cuminum cyminum) and turmeric (Curcuma longa) inhibitplatelet aggregation and alter eicosanoid biosynthesis in human blood platelets. Prostaglandins Lekuot Essent Fatty Acids 37(1): 5764.

67. Willatgamuwa SA, Platell K, Saraswathi G, Srinivasan K (1998) Antidiabetic influence of dietary cumin seeds (Cuminum cyminum) in streptozotocin induced diabetic rats. Nutrition Research 18(1): 131142.

68. Karnick CR (1991) A clinical trial of a composite herbal drug in the treatment of diabetes mellitus. Aryavaidyan 5: 36-46.

69. Derakhshan S, Sattari, Bigedli M (2007) Evaluation of antibacterial activity and biofilm formation in Klebsiellap neumoniae in contact with essential oil and alcoholic extract of cumin seed (cuminum cyminum). 17th European Congress of Clinical Microbiology and Infectious Diseases ICC, Munich, Germany 29(2): S601.

70. Gagandeep, Dhanalakshmi S, Mendiz E, Rao AR, Kale RK (2003) Chemopeventive effects of Cuminum cyminum in chemically induced for stomach and uterin complex cervix tumours in murine model systems. Nutr. Cancer 47(2): 171-180.

71. Santos AG, Figueiredo AC, Lourenco PM, Barrosa JG, Pedro LG (2002) Hairy root cultures of Anethum graveolens (dill): Establishment, growth, time-course study of their essential oil and its comparison with parent plant oils. Biotech Lett 24(12): 1031-1036.

72. Blank I, Grosch W (1991) Evaluation of potent odorants in dill seed and dill herb (Anethum graveolens L.) by aroma extract dilution analysis. J Food Sci 56(1): 63-67.

73. Bonnlander B, Winterhalter P (2000) 9-Hydroxypiperitone beta-Dglucopyranoside and other polar constituents from dill (Anethum graveolens L.) herb. J Agric Food Chem 48(10): 4821-4825.

74. Bouwmeester HJ, Gershenzon J, Konings MC, Croteau R (1998) Biosynthesis of the monoterpenes limonene and carvone in the fruit of caraway. I. Demonstration Of enzyme activities and their changes with development. Plant Physiol 117(3): 901-912.

75. Raghvan B, Abrahman KO, Koller WD, Shankarnarayanan ML (1994) Studies on flavor changes during drying of Dill (Anethum sowa. Roxb) leaves. J Food Qual 17(6): 457-466.

76. Score C, Lorenzi R, Ranall P (1997) The effect of S-(+)-carvone treatments on seed potato tuber dormancy and sprouting. Potato Res. 40(2): 155-161.

77. Vigushin DM, Poon GK, Boody A, English J, Halbert GW, et al. (1998) Phase I and pharmacokinetic study of D-limonene in patients with advanced cancer. Cancer Research Campaign Phase I/II Clinical Trials Committee. Cancer Chemother Pharmacol 42(2): 111-117. 
78. Duke JA (2001) Handbooke of Medicinal Herbs. In Duke JA (Eds) London: CRC Press, USA p. 42.

79. Dhalwal K, Shinde VM, Mahadik KR (2008) Efficient and sensitive method for quantitative determination and validation of Umbelliferone, carvone and Myristicin in Anethum graveolens and Carum carvi seeds. Chromatograph. 67(1-2): 163-167.

80. Newberne P, Smith RL, Doull J, Goodman JI, Munro IC, et al. (1999) The FEMA GRAS assessment of trans-anethole used as a flavoring substance. Flavor and Extract Manufacturer's Association. Food Chem Toxicol 37(7): 789 - 811.

81. Pulliah T (2002) Medicinal Plants in India. Vol. 1. New Delhi: Regency Publications New Delhi p. 55-56.

82. SS Meena, G Lal, RS Mehta, K Kant, MM Anwer (2010) Seed spices for home remedies. Indian Horticulture, Jul-Aug p. 6-8.

83. Hornok L (1992) Cultivation and processing of medicinal plants: Academic publications 338.

84. Fleming T (2000) PDR for Herbal Medicines. Medical Economics Company, New Jersey, USA p. 252.

85. Nair R, Chanda S (2007) Antibacterial activities of some medicinal plants of the western region of India. Turk J Biol 31: 231-236.

86. A Yili, H Yimamu, VV Maksimov, HA Aisa, ON Veshkurova, Sh I Salikhov (2006) Chemical composition of essential oil from seeds of Anethum graveolens cultivated in China. Chemistry of Natural Compounds 42(4): 491-449.

87. JacekSłupski, ZofiaLisiewska, Waldemar Kmiecik (2005) Contents of macro and microelements in fresh and frozen dill (Anethum graveolensL.) 91(4): 737-743.

88. Gurinder J Kaur, Daljit S Arora (2009) Antibacterial and phytochemical screening of Anethum graveolens, Foeniculum vulgare and Trachyspermum ammi. BMC Complementary and Alternative Medicine The official journal of the International Society for Complementary Medicine Research (ISCMR).

89. Katya P Svoboda and Janice B Hampson (1999) Bioactivity of essential oils of selected temperate aromatic plants: antibacterial, antioxidant, antiinflammatory and other related pharmacological activities. Plant Biology Department, SAC Auchincruive, Ayr, Scotland, UK.

90. Syed Faisal Haider Zaidi, Kazuki Yamada, Makoto Kadowaki, Khan Usmanghani, Toshiro Sugiyama (2009) Bactericidal activity of medicinal plants, employed for the treatment of gastrointestinal ailments, against Helicobacter pylori. Journal of Ethnopharmacology 121(2): 286-291.

91. Tanira, MOM, Shah AH, Mohsin A, Ageel AM, Qureshi, S (1996) Pharmacological and toxicological investigations on F. vulgare dried fruit extract in experimental animals. PhytotherRes 10(1): 33-36.

92. Raffo A, Nicoli S, Leclercq C (2011) Quantification of estragole in fennel herbal teas: Implications on the assessment of dietary exposure to estragole. Food Chem Toxicol 49(2): 370-375.

93. Piccaglia R, Marotti M (2001) Characterization of some Italian types of wild fennel (Foeniculum vulgare Mill.). J Agric Food Chem Jan 49(1): $1239-1244$

94. Bilia AR, Fumarola M, Gallori S, Mazzi G, Vincieri FF (2000) Identification by HPLC-DAD and HPLC-MS analyses and quantification of constituents of fennel teas and decoctions. J Agric Food Chem 48(10): 4734-4738.

95. Napoli, EM, Curcuruto G, Ruberto G (2010) Screening the essential oil composition of wild Sicilian fennel. Biochem Syst Ecol 38(2): 213-223.

96. Reiter B, Lechner M, Lorbeer E (1998) The fatty acid profiles-including petroselinic and cis-vaccenic acid-of different umbelliferae seed oils. Fett Lipid 100(11): 498-502.
97. Singh G, Maurya S, De LMP, Catalan C (2006) Chemical constituents, antifungal and antioxidative potential of $\mathrm{F}$. vulgare volatile oil and its acetone extract. Food Control 17: 745-752.

98. Parejo I, Viladomat F, Bastida J, Schmeda-Hirschman G, Burillo J, et al. (2004) Bioguided isolation and identification of the nonvolatile antioxidant compounds from fennel (F. vulgare Mill.) waste. J Agric Food Chem 52(7): 1890-1897.

99. Harborne JB, Boardley M (1984) Use of high-performance liquid chromatography in the separation of flavonol glycosides and flavonol sulphates. J Chromatogr 299: 377-385.

100. Khan IA, Abourashed EA (2009) Leung's Encyclopedia of Common Natural Ingredients Used in Food Drugs and Cosmetics ( $3^{\text {rd }}$ Edn.) New York: John Wiley and Sons, Inc pp. 183-186.

101. Choi EM, Hwang JK (2004) Anti-inflammatory, analgesic and antioxidant activities of the fruit of Foeniculum vulgare. Fitoterapia 75(6): 557-565.

102. Ruberto G, Baratta MT, Deans SG, Dorman, HJ (2000) Antioxidant and antimicrobial activity of F. vulgare and C. maritimum essential oils. Planta Med 66(8): 689-693.

103. Oktay M, Gulcin I, Kufrevioglu I (2003) Determination of in vitro antioxidant activity of fennel (Foeniculum vulgare) seed extracts. FoodSci Tech 36(2): 263-271.

104. Joshi $H$ (2006) Cholinergic basis of memory-strengthening effect of $F$. vulgare Linn. J FoodMed 9(3): 413-417.

105. Kwon YS, Choi WG, Kim WJ, Kim WK, Kim MJ, etal. (2002) Antimicrobial constituents of Foeniculum vulgare. Arch Pharm Res 25(2): 154-157.

106. Araque M, Rojas LB, Usubillaga A (2007) Antibacterial activity of essential oil of $\mathrm{F}$. vulgare Miller against multiresistant Gram-negative bacilli from nosocomial infections. Science 15(3): 366-370.

107. Mimica-Dukiæ N, Kujundžiæ S, Sokoviæ M, Couladis M (2003) Essential oils composition and antifungal activity of F. vulgare Mill. Obtained by different distillation conditions. Phytother Res 17(4): 368-371.

108. Park SH, Seong I (2010) Antifungal effects of the extracts and essential oils from F. vulgare and Illicium verum against Candida albicans. Korean J Med Mycol 15(4): 157-164.

109. Shahat AA, Ibrahim AY, Hendawy SF, Omer EA, Hammouda FM, AbdelRahman FH, Saleh MA (2011) Chemical composition, antimicrobial and antioxidant activities of essential oils from organically cultivated fennel cultivars. Molecules 16(2): 1366-1377.

110. Faudale M, Viladomat F, Bastida J, Poli F, Codina C (2008) Antioxidant activity and phenolic composition of wild, edible, and medicinal fennel from different Mediterranean countries. J Agric Food Chem 56(6): 1912-1920.

111. Lee HS (2004) Acaricidal activity of constituents identified in F. Vulgare fruit oil against Dermatophagoides spp. (Acari: Pyroglyphidae). J Agric Food Chem 52(10): 2887-2889.

112. Albert-Puleo M (1980) Fennel and anise as estrogenic agents. J. Ethnopharm 2(4): 337-344.

113. Conti B, Canale A, Bertorli A, Gozzini F, Piselli L (2010) Essential oil composition and larvicidal activity of six Mediterranean aromatic plants against the mosquito Aedes albopictus (Diptera: Culicidae). Parasitol Res 107(6): 1455-1461.

114. Ozbek H, Ugras S, Dulger H, Bayram I, Tuncer I, et al. (2003) Hepatoprotective effect of F. vulgare essential oil. Fitoterapia 74(3): 317-319.

115. Yoshikawa M, Murakami T, Komatsu H, Murakami N, Yamahara J, Matsuda H (1997) Medicinal foodstuffs. IV. Fenugreek seed. (1): structures of trigoneosides Ia, Ib, IIa, IIb, IIIa, and IIIb, new furostanol saponins from the seeds of Indian Trigonella foenum-graecum L. Chem Pharm Bull(Tokyo) 45(1): 81-87. 
116. Ahmadiani A, Javan M, Semnanian S, Barat E, Kamalinejad M (2001) Anti-inflammatory and antipyretic effects of Trigonella foenumgraecum leaves extract in the rat. J Ethnopharmacol 75(2-3): 283-286.

117. Petit P R, Sauvaire YD, Hillaire-Buys DM, Leconte OM, Baissac YG, et al. (1995) Steroid saponins from fenugreek seeds: extraction, purification, and pharmacological investigation on feeding behavior and plasma cholesterol. Steroids 60(10): 674-680.

118. Sauvaire Y, Baissac Y, Leconte O, Petit P, Ribes G (1996) Steroid saponins from fenugreek and some of their biological properties. Adv Exp Med Biol 405: 37-46.

119. Raghuram TC, Sharma RD, Sivakumar B, Sahay BK (1994) Effect of fenugreek seeds on intravenous glucose disposition in non-insulindependent diabetic-patients. Phytother Res 8(2): 83-86.

120. Srichamroen A, Field CJ, Thomson ABR, Basu TK (2008) The modifying effects of galactomannan from Canadian-grown fenugreek (Trigonella foenum-graecum L.) on the glycemic and lipidemic status in rats. J Clin Biochem Nutr 43(3): 167-174.

121. Sharma RD, Raghuram TC, Rao NS (1990) Effect of fenugreek seeds on blood-glucose and serum-lipids in type-I diabetes. Eur J Clin Nutr 44(4): 301-306.

122. Sharma RD, Sarkar A, Hazra DK, Mishra B, Singh JB, Sharma SK, Maheshwari BB, Maheshwari PK (1996) Use of fenugreek seed powder in the management of non-insulin dependent diabetes mellitus. Nutr Res 16(8): 1331-1339.

123. Fairchild RM, Ellis PR, Byrne AJ, Luzio SD, Mir MA (1996) A new breakfast cereal containing guar gum reduces postprandial plasma glucose and insulin concentrations in normal-weight human subjects. Br J Nutr 76(1): 63-73.

124. Sels JP, Flendrig JA, Postmes TJ (1987) The influence of guar gum bread on the regulation of diabetes mellitus type II in elderly patients. $\mathrm{Br} J$ Nutr 57(2): 177-180.

125. Landin K, Holm G, Tengborn L, Smith U (1992) Guar gum improves insulin sensitivity, blood-lipids, blood-pressure, and fibrinolysis in healthy-men. Am J Clin Nutr 56(6): 1061-1065.

126. Krishnaswamy, K (2008) Traditional indian spices and their health significance, Asia. Pac J Clin Nutr 17(1): 265-268.

127. Ashihara, H (2006) Metabolism of alkaloids in coffee plants. Braz J Plant Physiol 18(1): 1-8.

128. Chapagain B, Wiesman Z (2005) Variation in diosgenin level in seed kernels among different provenances of Balanites aegyptiaca and its correlation with oil content. Afr J Biotechnol 4(11): 1209-1213.

129. Balaraman R, Dangwal S, Mohan M (2006) Antihypertensive effect of Trigonella foenum-greacum seeds in experimentally induced hypertension in rats. Pharmaceut Biol 44(8): 568-575.

130. Mitra A, Bhattacharya DP (2006) Effects of fenugreek in type 2 diabetes and dyslipidaemia, Indian J Practising Doctor 3(2): 14-18.

131. Sebastiana KS, Thampanb RV (2007) Differential effects of soybean and fenugreek extracts on the growth of MCF-7 cells, Chemico-Biol Interactions 170(2): 135-143.

132. Al-dalain S, El-kutry MS, Ibrahim HS (2008) Inhibitory effect of aqueous extracts of barley and fenugreek on ulcer induction in rats. World AppSci 5(3): 332-339.

133. Mathern JR, Raatz SK, ThomasW, Slavin JL (2009) Effect of fenugreek fiber on satiety, blood glucose and insulin response and energy intake in obese subjects. Phytother Res 23(11): 1543-1548.

134. Gupta SK, Kalaiselvan V, Srivastava S, Saxena R, Agrawal SS (2010) Trigonellafoenum-graecum (fenugreek) protects againstseleniteinduced oxidative stress in experimental cataractogenesis. Biol Trace Elem Res 136(3): 258-268.
135. Rathore SS, Parul M, Saxena R, Saxena, S N (2012) b. Effect of cryogenic grinding on fatty acid composition of fenugreek (Trigonella foenumgracium L.) genotypes. In: National seminar "Harnessing Seed Spices for Better Socio Economic Well Being held on 6-7 January 2012 at DAV College, Ajmer 3(1): 26-30.

136. El-Soud NHA, Khalil MY, Hussein JS, Oraby FSH, Farrag ARH (2007) Antidiabetic effects of fenugreek alkaliod extract in streptozotocin induced hyperglycemic rats. J Appl Sci Res 3: 1073-1083.

137. Stark A, Madar Z (1993) The effect of an ethanol extract derived from fenugreek (Trigonellafoenum-graecum) on bile acid absorption and cholesterol levels in rats. British J Nutr 69(1): 277-287.

138. Devi BA, Kamalakkannan N, Prince PSM (2003) Supplementation of fenugreek leaves to diabetic rats. Effect on carbohydrate metabolic enzymes in diabetic liver and kidney. PhytotherRes 17(10): 12311233.

139. Puri D, Prabhu KM, Murthy PS (2002) Mechanism of action of a hypoglycemic principle isolated from fenugreek seeds. Indian J Physiol Pharmacol 46(4): 457-462.

140. Amin A, Alkaabi A, Al-Falasi S, Daoud SA (2005) Chemopreventive activities of Trigonella Foenum Graecum against breast cancer. Cell Biol Intern 29(8): 687-694.

141. Raju J, Patlolla JMR, Swamy MV, Rao CV (2004) Diosgenin, a steroid saponin of Trigonella Foenum Graecum (fenugreek), inhibitsazoxymethane-induced aberrant crypt foci formation in $\mathrm{f} 344$ rats and induces apoptosis in HT-29 human colon cancer cells, Cancer. Epidemiol Biomarkers Prev 13(8): 1392- 1398.

142. Dixit P, Ghaskadbi S, Mohan H, Devasagayam TPA (2005) Antioxidant properties of germinated fenugreek seeds. Phytother Res 19(11): 977983.

143. Kaviarasan S, Vijayalakshmi K, Anuradha CV (2004) Polyphenol rich extract of fenugreek seeds protect erythrocytes from oxidative damage. Plant Foods Human Nut 59(4): 143-147.

144. Genet S, Kale RK, Baquer NZ (2002) Alterations in antioxidant enzymes and oxidative damage in experimental diabetic rat tissues: Effect of vanadate and fenugreek (Trigonellafoenum graecum). Molecular Cell Biochem 236(1-2): 7-12.

145. Anuradha CV, Ravikumar P (2001) Restoration on tissue antioxidants by fenugreek seeds (Trigonella foenum -graecum) in alloxandiabetic rats. Indian J Physiol Pharmacol 45: 408-420.

146. Saxena SN, Rathore SS, Saxena R (2011) Effect of cryogenic grinding on medicinally important compounds and antioxidant properties of seed extract of fenugreek (Trigonella foenum-graecum L.) genotypes. In National seminar on "Emerging trends in Spice Processing and its Impact on Rural Economy" held at CTAE, Udaipur on 17-18.

147. Yunbao L, Kakani R, Nair MG (2012) Compounds in functional food fenugreek spice exibite anti-inflammatory and antioxidant activities. Food Chemistry 131(4): 1187-1192.

148. Sharififara F, Khazaelia P, Allib N (2009) In vivo evaluation of antiinflammatory activity of topical preparations from fenugreek (Trigonellafoenum-graecum L.) seeds in a cream base. Iranian J Pharmaceut Sci 5(3): 157-162.

149. Abdullah MA, Al-Bayati FH, Ali NAW, Baharuddin NA (2007) Wound healing potential of Ageratum conyzoides, Trigonellafoenumgraceum and Ginkgo biloba paste in rats. Dentika Dental J 12: 22-25.

150. Talpur N, Echard B, Ingram C, Bagchi D (2005) Effects of a novel formulation of essential oils on glucose-insulin metabolism in diabetic and hypertensive rats: a pilot study. Diab Obes Metab 7(2): 193-199.

151. Rohini RM, Nayeem M, Das AK (2009) Diuretic effect of Trigonella foenum- graecum seed extracts. Intern J Altern Med 6: 2. 
152. Panda S, Tahiliani P, Kar A (1999) Inhibition of triiodothyronine production by fenugreek seed extract in mice and rats. Pharmacol Res 40(5): 405-409.

153. Ahsan SK, Tabiq M, Ageel AM, Al-Yahya MA, Shah AH (1989) Effect of Trigonellafoenumgraecum and Ammi majus on calciumoxalate urolithiasis in rats. J. Ethnopharmacol 26(3): 249-54.

154. Palaniswamy M, Pradeep BV, Sathya R, Angayarkanni J (2008) In vitro anti-plasmodial activity of Trigonella foenum-graecum. e CAM 7(4): 441-445.

155. Khare CP (2004) Encyclopedia of Indian medicinal plants. NewYork: Springes-Verlag Berlin Heidelberg;

156. Sharma PC, Yelne MB, Dennis TJ (2005) Database on medicinal plants used in Ayurveda. New Delhi: pp. 420-440.

157. Goreja WG (2003) Black seed: nature's miracle remedy. Amazing Herbs Press, New York, USA.

158. Al-Bukhari MI (1976) In: The collection of authentic sayings of prophet Mohammad (peace be upon him), division 71 on medicine ( $\left.2^{\text {nd }} E d n.\right)$.

159. Abel-Salam BK (2012) Immunomodulatory effects of black seeds and garlic on alloxan-induced diabetes in albino rat. Allergol Immunopathol (Madr) 40(6): 336-340.

160. Al-Ali A, Alkhawajah AA, Randhawa MA, Shaikh NA (2008) Oral and intraperitoneal LD50 of thymoquinone, an active principle of Nigella sativa, in mice and rats. J Ayub Med Coll Abbottabad 20(2): 25-27.

161. Al-Jassir MS (1992) Chemical composition and microflora of black cumin (Nigella sativaL.) seeds growing in Saudi Arabia. Food Chem 45(4): 239-242.

162. Atta-Ur-Rahman (1995) Nigellidine-a new indazole alkaloid from the seed of Nigella sativa. Tetrahedron Lett 36(12): 1993-1994.

163. Nickavar B, Mojab F, Javidnia K, Amoli MA (2003) Chemical composition of the fixed and volatile oils of Nigella sativa L. from Iran. Z Naturforsch C 58(9-10): 629-631.

164. Cheikh-Rouhou S, Besbes S, Lognay G, Blecker C, Deroanne C, et al. (2008) Sterol composition of black cumin (Nigella sativa L.) and Aleppo pine (Pinus halpensis Mill.) seed oils. J Food Comp Anal 21(2): 162-168.

165. Bourgou S, Ksouri R, Bellila A, Skandrani I, Falleh H, Marzouk B (2008) Phenolic composition and biological activities of Tunisian Nigella sativa L. shoots and roots. C R Biol 331(1): 48-55.

166. Nickavar B, Mojab F, Javidnia K, Amoli MA (2003) Chemic al composition of the fixed and volatile oils of Nigella sativa L. from Iran. Z Naturforsch C 58 (9-10): 629-631.

167. Mehta BK, Pandit V, Gupta M (2009) New principles from seeds of Nigella sativa. Nat Prod Res 23(2): 138-148.

168. Warrier PK, Nambiar VPK, Ramankutty (2004) Chennai: Orient Longman Pvt Ltd; Indian medicinal plants-a compendium of 500 species pp. 139-142.

169. Yarnell E, Abascal K (2011) Nigella sativa: holy herb of the middle East. Altern Compl Therap 17(2): 99-105.

170. Padhye S, Banerjee S, Ahmad A, Mohammad R, Sarkar FH (2008) From here to eternity-the secret of Pharaohs: Therapeutic potential of black cumin seeds and beyond. Cancer Ther 6: 495-510.

171. Hanafy M S and HatemM E (1991) Studies on the antimicrobial activity of Nigella sativaseed (black cumin). Journal of Ethnopharmacology 34(2-3): 275 - 280.

172. Kahsai AW (2002) Isolation and characterization of active ingredients from Nigella sativa for antibacterial screening. MSc thesis (Chemistry), East Tennessee State University, USA.
173. Chaieb K, Kouidhi B, Jrah H, Mahdouani K, Bakhrouf A (2011) Antibacterial activity of Thymoquinone, an active principle of Nigella sativa and its potency to prevent bacterial biofilm formation. BMCComplementary and Alternative Medicine 11: 29-33.

174. Morsi N M (2000) Antimicrobial effect of crude extracts of Nigella sativa on multiple antibiotics-resistant bacteria. Acta Microbiol Pol 49(1): 63-74.

175. Bakathir H A, Abbas N A (2011) Detection of the antibacterial effect of Nigella sativa ground seeds with water. African Journal of Traditional, Complementary and Alternative Medicine 8(2): 159-164.

176. Salem E M, Yar T, Bamosa AOA, Al-Quorain MIRM, Alsulaiman Y (2010) Comparative study of Nigella sativa and triple therapy in eradication of Helicobacter Pylori in patients with non-ulcer dyspepsia. Saudi Journal of Gastroenterology 16(3): 207-214.

177. Hannan A, Saleem S, Chaudhary S, Barka M, Arshad MU (2008) Antibacterial activity of Nigella sativa against clinical isolates of methicillin resistant Staphylococcus aureus. Journal of Ayub Medical College 20(3): 72-74.

178. Bita A, Rosu AF, Calina D, Rosu L, Zlatian O, Dindere C (2012) An alternative treatment for Candida infections with Nigella sativa extracts. Eur J Hosp Pharm 19(2): 162.

179. Halamova K, Kokoska L, Flesar J, Sklenickova O, Svobodova B, Marsik P (2010) In vitro antifungal effect of black cumin seed quinones against dairy spoilage yeasts at different acidity levels. J Food Prot 73 (12): 2291-2295.

180. Rogozhin EA, Oshchepkova YI, Odintsova TI, Khadeeva NV, Veshkurova ON, Egorov TA (2011) Novel antifungal defensins from Nigella sativa L. seeds. Plant Physiol Biochem 49(2): 131-137.

181. Mahmoud MR, El-Abhar HS, Saleh S (2002) The effect of Nigella sativa oil against the liver damage induced by Schistosoma mansoni infection in mice. J Ethnopharmacol 79 (1): 1-11.

182. MariodAA, IbrahimRM, Ismail M, IsmailN (2009) Antioxidant activity and phenolic content of phenolic rich fractions obtained from black cumin (Nigella sativa) seed cake. Foodhemistry 116(1): 306 - 312.

183. Sogut B, Celik I, Tuluce Y (2008) The effects of diet supplemented with the black Cumin (Nigella sativa L.) upon immune potential and antioxidant marker enzymes and lipid peroxidation in broiler chicks. Journal of Animal and Veterinary Advances 7(10): 1196-1199.

184. Baldioli M, Servili M, Perretti, GMontedoroGF (1996) Antioxidant activity of tocopherols and phenolic compounds of virginolive oil. Journal of the American Oil Chemists Society 73(11): 1589-1583.

185. Burits M, Bucar F (2000) Antioxidant activity of Nigella sativa oil. Phytotherapy Research 14:323-328.

186. Ramadan M F, Morsel J T (2004) Oxidative stability of black cumin (Nigella sativa L.), coriander (Coriandrum sativum L.) and niger. Food Chemistry 106(1): 385-389.

187. Turkdogan M K, Ozbek H, Yener Z, Tuncer I, Uygan I, et al. (2003) The role of Urtica dioica and Nigella sativa in the prevention of carbon tetrachloride-induced hepatotoxicity in rats. Phytotherapy Research 17(8): 942-946.

188. Benhaddou-Andaloussi A, Martineau L, Danielle S, Vuong T, Leduc C, et al. (2008) Antidiabetic activity of Nigella sativa. Seed extract in cultured pancreatic $\beta$-cells, skeletal muscle cells, and adipocytes. Pharmaceutical biology 46(1-2): 1-29.

189. Benhaddou-Andaloussi A, Martineau L, Vuong T, Meddah B, Madiraju P, et al. (2011) The in vivo antidiabetic activity of Nigella sativa is mediated through activation of the AMPK pathway and increased muscle glut4 content. Evid Based Complementary Alternate Med 53: 86-91. 
190. Salama R H (2011) Hypoglycemic effect of lipoic acid, carnitine and Nigella sativa in diabetic rat model. International Journal of Health Science. (Qassim) 5(2): 126-134.

191. Alam S, Reddy S K, Baig A, Reddy M K, Mohiuddin M, Reddy M V, Gupta R K (2013) Evaluation of Anti-Diabetic and Anti-Lipidimic potential of kalongi sugar powder water extract in stz induced diabetic Rats. International Journal of Pharmacy and Pharmaceutical Sciences 5(1): 22-28.

192. Kapoor S (1999) Emerging clinical and therapeutic applications of Nigella sativa in stroenterology. World Journal of Gastroenterology 15(17): 2170-2171.

193. Bamosa A O, Kaatabi H, Lebdaa F M, Elq A M and Al-Sultan A (2010) Effect of Nigella sativa seeds on the glycemic control of patients with type 2 Diabetes mellitus. Indian Journal of Physiology and Pharmacology 54(4): 344-354.

194. Rchid H, Chevassus H, Nmila R, Guiral C, Petit F, et al. (2004) Nigella sativa seed extracts enhance glucose- induced insulin release from rat isolated Langerhans islets. Fundamental and Clinical Pharmacology 18(5): 525-529.

195. Najmi A, Haque S F, Naseeruddin M, Khan R A (2008) Effect of Nigella sativa oil on various clinical and biochemical parameters of metabolic syndrome. Int J Diabetes Dev Ctries 28(1): 11-14.

196. Salomi MJ, Nair SC, Panikkar KR (1991) Inhibitory effects of Nigella sativa and Saffron (Crocus sativus) on chemical carcinogenesis in mice. Nutrition and Cancer 16(1): 67-72.

197. Kumara SS, Huat BT (2001) Extraction,isolationand characterization of anti-tumor principle, alpha hederin from the seeds of Nigellasativa. PlantaMedica 67(1): 29-32.

198. Nazrul-Islam SK, Begum F, Ahsan T, Hague MAS (2004) Immunosuppressive and cytotoxic properties of Nigella sativa. Phytotherapy Research 18(5): 395-398.

199. Rooney S, Ryan MF (2005) Modes of action of alpha-hederin and thymoquinone, active constituents of Nigella sativa against HEP-2 cancer cells. Anticancer Research 25(6B): 4255-4259.

200. Harzallah HJ, Grayaa R, Kharoubi W, Maaloul A, Hammami M, et al. (2012) Thymoquinone, the Nigella sativa bioactive compound, prevents circulatory oxidative stress caused by 1,2-dimethylhydrazine in erythrocyte during colon post initiation carcinogenesis. Oxidative Medicine and Cell Longevity 12: 854-865.

201. Jeong HG (1998) Suppression of constitutive and inducible cytochrome P450 gene expression by alpha hederin in mice. Biochemistry and Molecular Biololgy International 46(5): 1019-1026.

202. Salim EI and Fukushima S (2003) Chemopreventive potential of volatile oil from black cumin (Nigella sativa) seeds against rat colon carcinogenesis. Nutrition and Cancer 45(2): 195-202.

203. El-Obeid A S, Haseeb A M, Poten F, Westermark B (2006) The effect of herbal melanin on Il-8. A possible role of Toll-like receptor4 (TLR4) Biochemistry and Biophysics Research Communication 344(4): 12001206.

204. Worthen D R, Ghosheh O A, Crooks P A (1998) The in vitro antitumor activity of some crude and purified components of black seed, Nigella sativa L. Anticancer Research 18(3A): 1527-1532.

205. Mutabagani A, El-Mahdy SAM (1997) A study of the anti- inflammatory activity of Nigella sativa L. and thymoquinone in rats. Saudi Pharm J 5(2): 110-113.

206. Shuid AN, Mohamed N, Mohamed IN, Othman F, Suhaimi F, et al. (2012) Nigella sativa: A potential antiosteoporotic agent. Evid Based Compl Altern Med 2012: 696230.

207. Nikakhlagh S, Rahim F, Aryani FH, Syahpoush A, Brougerdnya MG, et al. (2011) Herbal treatment of allergic rhinitis: the use of Nigella sativa. Am J Otolaryngol 32(5): 402-407.
208. Majdalawieh AF, Hmaidan R, Carr RI (2010) Nigella sativa modulates splenocyte proliferation, Th1/Th2 cytokine profile, macrophage function and NK anti-tumor activity. J Ethnopharmacol 131(2): 268275.

209. Torres MP, Ponnusamy MP, Chakraborty S, Smith LM, Das S, Arafat HA (2010) Effects of thymoquinone in the expression of mucin 4 in pancreatic cancer cells: implications for the development of novel cancer therapies. Mol Cancer Ther 9(5): 1419-1431.

210. Assayed ME (2010) Radioprotective effects of black seed (Nigella sativa) oil against hemopoietic damage and immunosuppression in gamma-irradiated rats. Immunopharmacol Immunotoxicol 32(2): 284-296.

211. Boskabady MH, Keyhanmanesh R, Khameneh S, Doostdar Y, Khakzad MR (2011) Potential immunomodulation effect of the extract of Nigella sativa on ovalbumin sensitized guinea pigs. J Zhejiang Univ Sci B 12(3): 201-209.

212. Al Mofleh IA, Alhaider AA, Mossa JS, Al-Sohaibani MO, Al-Yahya MA Rafatullah S (2008) Gastroprotective effect of an aqueous suspension of black cumin Nigella sativa on necrotizing agents-induced gastric injury in experimental animals. Saudi J Gastroenterol 14(3): 128-134.

213. Khaled AAS (2009) Gastroprotective effects of Nigella sativa oil on the formation of stress gastritis in hypothyroidal rats. Int J Physiol Pathophysiol Pharmacol 1(2): 143-149.

214. Lei X, Liu M, Yang Z, Ji M, Guo X, Dong W (2012) Thymoquinone Prevents and ameliorates dextran sulfate sodium-induced colitis in mice. Dig Dis Sci 57(9): 2296-2303.

215. Yildiz F, Coban S, Terzi A, Ates M, Aksoy N, Cakir H (2008) Nigella sativa relieves the deleterious effects of ischemia reperfusion injury on liver. World J Gastroenterol 14(33): 5204-5209.

216. Kapoor S (2009) Emerging clinical and therapeutic applications of Nigella sativa in gastroenterology. World J Gastroenterol 15(17): 21702171.

217. Swamy S M, Huat BT (2003) Intracellular glutathione depletion and reactive oxygen species generation are important in alpha- hederininduced apoptosis of P388 cells. Molecular Cell Biochemistry 245(12): 127-139.

218. Al-Naggar TB, Gomez-Serranillos MP, Carretero ME, Villar AM (2003) Nephropharmacological activity of Nigella sativa L. extracts. Journal of Ethnopharmacology 88(10): 63-68.

219. Saleem U, Ahmad B, Rehman K, Mahmood S, Alam M, et al. (2012) Nephro-protective effect of vitamin $\mathrm{C}$ and Nigella sativa oil on gentamicin associated nephrotoxicity in rabbits. Pakistan Journal of Pharmacology Science 25(4): 727-730.

220. Wienkotter N, Höpner D, Schütte U, Bauer K, Begrow F, El-Dakhakhny M (2008) The effect of nigellone \& thymoquinone on inhibiting trachea contraction and mucociliary clearance. Plant Med 74(2): 105-108.

221. Boskabady MH, Keyhanmanesh R, Saadatloo MA (2008) Relaxant effects of different fractions from Nigella sativa L. on guinea pig tracheal chains and its possible mechanism(s) Indian J Exp Biol 46(12): 805-810.

222. Kanter M(2009) Effects of Nigella sativa seed extract on ameliorating lung tissue damage in rats after experimental pulmonary aspirations. Acta Histochem 111(5): 393-403.

223. Boskabady MH, Mohsenpoor N, Takaloo L (2010) Antiasthmatic effect of Nigella sativa in airways of asthmatic patients. Phytomedicine 17(10): 707-713.

224. Gokce A, Oktar S, Koc A, Yonden Z (2011) Protective effects of thymoquinone against methotrexate-induced testicular injury. Hum Exp Toxicol 30(8): 897-903.

225. Akhtar M, Maikiyo AM, Khanam R, Mujeeb M, Aqil M, Najmi AK (2012) Ameliorating effects of two extracts of Nigella sativa in middle cerebral 
artery occluded rat. Journal of Pharmacy and Bioallied Science 4(1): 70-75.

226. Aqel M, Shaheen R (1996) Effects of the volatile oil of N.sativa seeds on the uterine smooth muscle of rat and guinea- pig. Journal of Ethnopharmacology 52(1): 23-26.

227. El-Naggar T, Gomez-Serranillos MP, Palomino OM, Arce C, Carretero ME (2010) Nigella sative L. seed extract modulates the neruotransmitter amino acids release in cultured neurons in vitro. Journal of Biomedical Biotechnology 12: 1-8.

228. Raza M, Alghasham AA, Alorainy MS, El-Hadiyah TM (2008) Potentiation of valproate-induced anticonvulsant response by Nigella sativa seed constituents: the role of GABA receptors. Int J Health Sci (Qassim) 2(1): 15-25.

229. Keshri G, Singh MM, Lakshmi V, Kamboj VP (1995) Post-coital contraceptive efficacy of the seeds of Nigella sativa in rats. Indian J Physiol Pharm 39(1): 59-62.

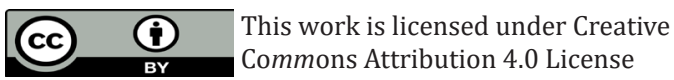

Submission Link: https://biomedres.us/submit-manuscript.php
230. Agarwal C, Narula A, Vyas DK, Jacob D (1990) Effect of seeds of kalaunji on fertility and sialic acid content of the reproductive organs of male rat. Geo Bios 17(5-6): 269-272.

231. Aqel M, Shaheen R (1996) Effects of the volatile oil of Nigella sativa seeds on the uterine smooth muscle of rat and guinea pig. J Ethnopharm 52(1): 23-26.

232. Zaoui A, Cherrah Y, Mahassini N, Alaoui K, Amarouch H, Hassar M (2002) Acute and chronic toxicity of Nigella sativa fixed oil. Phytomedicine 9(1): 69-74.

233. Khader M, Bresgen N, Eckl PM (2009) In vitro toxicological properties of thymoquinone. Food Chem Toxicol 47(1): 129-133.

234. Ali B, Amin S, Ahmad J, Ali A, Mohd Ali, et al. (2012) Bioavailability enhancement studies of amoxicillin with N. Indian J Med Res 135(4): 555-559.

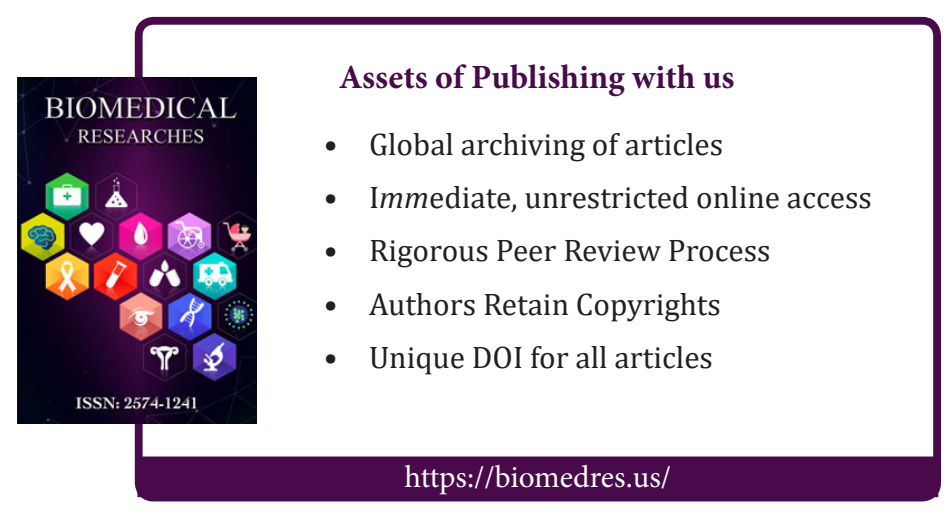

